

\section{Sumário}

I. Crônicas do Direito Internacional ...............................................1

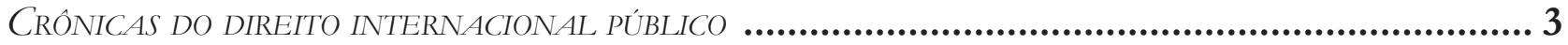

A resolução 2272 (2016) do Conselho de Segurança das Nações Unidas - O POSICIONAMENTO DA ONU FACE ÀS ALEGAÇÕES DE ABUSO E EXPLORAÇÃo SEXUAL POR SUAS

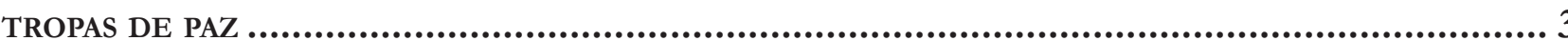

Sarah Dayanna Lacerda Martins Lima

CRÓNICAS DE DiREITo INTERNACIONAL PRIVADO...................................................................

Nadia de Araujo, Marcelo De Nardi, Gustavo Ribeiro, Fabrício Polido e Inez Lopes

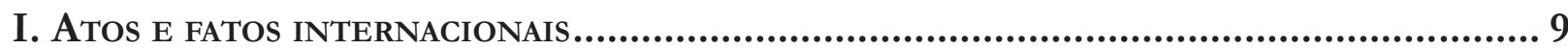

Crônica 1. Novidades de 2017 SObRE CIRCulaÇÃo faCilitada DE SENTENÇAS ESTRANGEIRAS 9

Crônica 2: O Direito Transnacional e os episódios das Carnes.........................................16

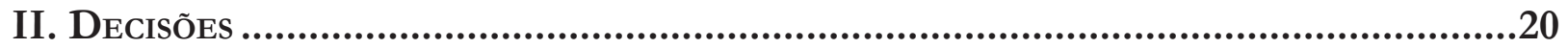

Crônica 3: A Irresistível ForÇa da ORDEM PÚblica E A HOMOLOGaÇÃo DE SENTENÇAS

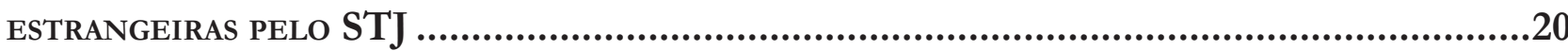

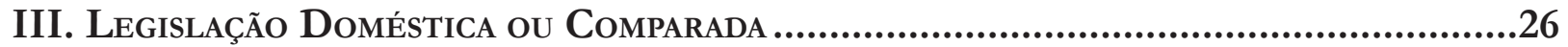

Crônica 4 - Dignidade da pessoa humana e mudança de paradigma da Lei de Migração

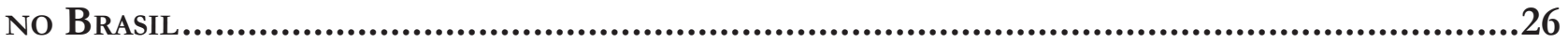

II. Dossiê especial: Direito Internacional dos InVEstimentos ................35

Non-adjudicatory State-State Mechanisms in Investment Dispute Prevention and Dispute Settlement: Joint Interpretations, Filters and Focal Points 
Mapping the Duties of Private Companies in International Investment Law .50 Nitish Monebhurrun

LA LÉGALITÉ DE L'INVESTISSEMENT DEVANT L'ARBITRE INTERNATIONAL: À LA RECHERCHE D'UN POINT D'ÉQUILIBRE .73 Hervé Ascensio

Host STATES AND STATE-STATE INVESTMENT ARBITRATION: STRATEGIES AND CHALlENGES......81 Murilo Otávio Lubamdo de Melo

Right to Regulate, Margin of Appreciation and Proportionality: Current Status in Investment Arbitration in Light of Philip Morris V. Uruguay. .95 Giovanni Zarra

Investments on Disputed Territory: Indispensable Parties and Indispensable Issues....122 Peter Tzeng

The Influence of General Exceptions on the Interpretation of National

Treatment in INTERNATIONAL INVESTMENT LAW. 140 Louis-Marie Chauvel

UMA PRoposta de REFleXão SObRe os ACFIs: Até QUE PONTO O TRATAMENTo de NAÇão MAIS FAVORECIDA PODE MINAR A ESTRATÉGIA POLÍTICA QUE OS EMBASA? 160

Michelle Ratton Sanchez Badin, Daniel Tavela Luis e Mario Alfredo de Oliveira

ECUADOR's 2017 TERMINATION OF TREATIES: HOW NOT TO EXIT THE INTERNATIONAL INVESTMENT REGIME 179

Jose Gustavo Prieto Muñoz

ONE BELT, ONE ROAD: NOVAS INTERFACES ENTRE O COMÉRCIO E OS INVESTIMENTOS INTERNACIONAIS 193

Flávio Marcelo Rodrigues Bruno e Marilda Rosado de Sá Ribeiro

III. Artigos Sobre outros TEMAS..................................................... 214

TolerânCIA E REFugIO: UM ENSAIO A PARTIR Do ACORdo EU-TurQUiA 216 Flávia Cristina Piovesan e Ana Carolina Lopes Olsen 
O TRATAMENTO do APÁtridA NA NOVA LEI DE MIGRAÇÃo: ENTRE AVANÇOS E RETROCESSOS...237 Jahyr-Philippe Bichara

O caráter humanista da Lei de Migrações: aVAnços da Lei N. 13.445/2017 E Os desafios DA REGULAMENTAÇÃO. 254 Marcelo Dias Varella, Clarice G. Oliveira, Mariana S.C. Oliveira e Adriana P. Ligiero

Reform of the United Nations Security Council: The Emperor Has No Clothes.268 Ljubo Runjic

A IDEIA DE QUe os LATINO-AMERICANOS PREFEREM O AUTORITARISMO À DEMOCRACIA À luz da reinterpretação dos Critérios do Programa das Nações Unidas para o DesenVolvimento 286

Gina Marcilio Pompeu e Ana Araújo Ximenes Teixeira

A PRoteção da ORIENTAÇÃo SEXUAL E IDENTIDAdE DE GÊNERO DIVERSAS NA CORTE PENAL internacional: Entre Realpolitiks E Os Direitos Humanos

Gustavo Bussmann Ferreira

A desnacionalização e as violações de direitos humanos na República Dominicana. 331 Daniela Menengoti Gonçalves Ribeiro e Rodrigo Ichikawa Claro Silva

CompetênCia do TPI no Caso do ATAque ao hospital de Kunduz: uma análise ENVOLVENDO A JURISDiÇÃo do TPI EM RELAÇÃO A NACIONAIS DE EsTAdOS NÃO-PARTE do Estatuto DE Roma

Filipe Augusto Silva e Renata Mantovani de Lima

A CRIMINALIZAÇÃo DOS IMIGRANTES EM SITUAÇÃo IRREGULAR NA ITÁliA: BIOPOLÍtica E DIREITO PENAL DO AUTOR.

Maiquel Angelo Dezordi Wermuth e Jeannine Tonetto de Aguiar

The New Rules On Trade And Environment Linkage In Preferential Trade Agreements

Alberto do Amaral Júnior e Alebe Linhares Mesquita

Beyond THE Border between the North and the South: towards a Decolonization of EPISTEMOLOGIES AND FIELDS OF RESEARCH ON MERCOSUR 
A aplicabilidade da Convenção de Montreal no direito brasileiro.

Aziz Tuffi Saliba e Alexandre Rodrigues de Souza

REgIME DE TRANSPARÊNCIA FISCAL NA TRIBUTAÇÃo DOS LUCROS AUFERIDOS NO EXTERIOR (CFC RULES): LACUNAS E CONFLITOS NO DIREITO BRASILEIRO

Paulo Rosenblatt e Rodrigo Torres Pimenta Cabral

As Regras Brasileiras de Tributação de Controladas e Coligadas no Exterior: verdadeiras Controlled Foreign Company (CFC) Rules? .......................................465

Melina de Souza Rocha Lukic e Amanda Almeida Muniz

O RETORNO DE BENS CULTURAIS

Aziz Saliba e Alice Lopes Fabris

Direitos culturais e Nações Unidas: uma análise a partir da Declaração Sobre a eliminação de Todas as Formas de Intolerância e Discriminação Baseadas na Religião OU NA CRENÇA

Leilane Serratine Grubba e Márcio Ricardo Staffen

OS REFLEXOS DA PROTEÇÃO INTERNACIONAL DA PROPRIEDADE INTELECTUAL PARA O DESENVOLVIMENTO INTERNO: UMA ANÁLISE SOBRE O SISTEMA PATENTÁRIO BRASILEIRO E A TRANSFERÊNCIA DE TECNOLOGIA

Michele M. Segala e Isabel Christine S. De Gregori

O CASO HIPOTÉTICO DA MORTE DO EMBAIXADOR FRANCÊS NA ESPANHA: DUAS ESPÉCIES DE IUS gentium em Francisco de Vitoria

Rafael Zelesco Barretto

De volta À BeVilaqua: anÁlise ECONÔMICA dA APLICAÇão do ART. $9^{\circ}$ DA LINDB Às OBRIGAÇÕES CIVIS CONTRATUAIS

Danielle Cristina Lanius e Ivo Teixeira Gico Jr 


\title{
A criminalização dos imigrantes em situação irregular na itália: biopolítica e direito penal do autor*
}

\author{
The criminalization of immigrants in \\ irregular situation in italy: biopolytics and \\ criminal law of the author
}

Maiquel Angelo Dezordi Wermuth**

Jeannine Tonetto de Aguiar***

\section{Resumo}

A percepção dos processos migratórios como problema de segurança nacional, principalmente a imigração irregular, levou à adoção pelos Estados de regulamentações jurídicas a partir das quais se assiste ao triunfo de políticas e práticas em total desrespeito aos direitos e garantias fundamentais humanos. Identificados e classificados como "sujeitos de risco", isto é, "inimigos" que ameaçam a ordem social, os imigrantes em condição de irregularidade migratória são transformados em objetos de um discurso criminalizador não apenas nos debates públicos e políticos, mas também na legislação, como é o caso da criminalização do imigrante irregular na legislação italiana analisado na presente pesquisa $3 / 4$ que evidencia um movimento de retrocesso do Direito Penal ao institucionalizar um modelo de Direito Penal de autor fundamentado em medidas de dominação e opressão que preconizam tão somente a exclusão desses sujeitos.

Palavras-chave: Direitos Humanos. Imigração irregular. Direito Penal. Biopolítica.

\begin{abstract}
The perception of migratory processes as a problem of national security, especially irregular immigration, led to the adoption by the States of legal regulations from which they can witness the triumph of policies and practices in total disregard for rights and guarantees human fundamental. Identified and classified as "subjects of risk", that is, "enemies" that threaten the social order, immigrants in the condition of migratory irregularity are transformed into objects of a criminalizing discourse not only in public and political debates, but also in legislation, such as the criminalization of the irregular immigrant in Italian - legislation analyzed in the present investigation - that shows a movement of retrogression of Penal Law when institutionalizing a model of Penal Law of author based on measures of domination and oppression that only recommend the exclusion of these subjects.
\end{abstract}

Keywords: Human Rights. Irregular immigration. Penal Law. Biopolitics.

* Recebido em 21/03/2017

Aprovado em 23/06/2017

** Doutor em Direito Público (UNISINOS); Professor dos Cursos de Direito da UNIJUÍ UNISINOS; Professor do Mestrado em Direitos Humanos da UNIJUÍ; Editor-chefe da Revista Direitos Humanos e Democracia. E-mail: madwermuth@gmail.com
*** Mestra em Direitos Humanos pela UNIJUÍ. E-mail : madwermuth@gmail.com 


\section{INTRODUÇÃO}

Caso 1: em 23 de fevereiro de 2012, a Corte Europeia de Direitos Humanos julgou o caso "Hirsi Jamaa e outros v. Itália", levado àquela Corte por um grupo de vinte e quatro cidadãos somalis e eritreus, que alegaram imediata expulsão coletiva sem análise devida dos casos, expondo-os a inúmeros riscos e maus tratos. De acordo com os fatos do caso, os imigrantes eram parte de um grupo de cerca de duzentas pessoas que deixaram a Líbia a bordo de três navios, com o objetivo de alcançar a costa italiana. Em 6 de maio de 2009, eles foram interceptados por três navios da guarda costeira e da Polícia da Receita italiana (Guardia di Finanza), sendo, posteriormente, transferidos para navios militares que os encaminharam para Trípoli, na Líbia.

Os recorrentes afirmaram que, durante essa viagem, não tiveram informações sobre seu destino pelas autoridades italianas, que, também, não tomaram qualquer medida para identificá-los, tendo sido, apenas, entregues às autoridades líbias quando da chegada ao porto de Trípoli, com base no acordo bilateral entre os Estados, assinado em 29 de dezembro de 2007. Dois cidadãos morreram em circunstâncias desconhecidas durante esses eventos ${ }^{1}$.

Caso 2: o caso Left-To-Die Boat, assim denominado por Charles Heller e Lorenzo Pezzani ${ }^{2}$ em relatório no âmbito do projeto Forensic Oceanography, evidencia, além do descaso nas interceptações e nas repatriações imediatas, outras situações de extrema violência nas ações e nos regimes de controle das fronteiras. Segundo o relato, em 27 de março de 2011, setenta e dois migrantes fugiam de Trípoli em um barco quando, no início da manhã, ficaram sem combustível e permaneceram à deriva por quatorze dias até retornarem novamente ao litoral da Líbia. Sem água e comida no barco, apenas nove desses migrantes sobreviveram. Em várias entrevistas, os sobreviventes relataram os contatos que tiveram com o mundo externo durante o período no mar, contatos que incluem um avião que sobrevoou sobre eles, o pedido de socorro enviado mediante telefones via satélite, um helicóptero militar que lançou alguns pacotes de biscoi-

1 EUROPEAN COURT OF HUMAN RIGHT. Case of Hirsi Jamaa and others v. Italy. 2012. Disponível em: <http://hudoc.echr. coe.int/>. Acesso em: 23 jan. 2016.

2 HELLER, Charles; PEZZANI, Lorenzo. Situ Studio: report on the "Left-To-Die Boat”. 2012. Disponível em: < https://www.fidh.org/ IMG/pdf/fo-report.pdf>. Acesso em: 28 jan. 2017. tos e algumas garrafas de água e um navio militar que não lhes ofereceu nenhuma assistência.

Ou seja, apesar dos pedidos de ajuda enviados ao órgão de resgate marítimo italiano e também da presença aérea e naval na área, em razão da intervenção militar na Líbia, nenhuma assistência foi prestada para evitar a morte de dezenas de migrantes em perigo no mar, em total violação aos Tratados e Convenções Internacionais de Direitos Humanos.

Esses dois casos, selecionados dentre tantos outros congêneres, revelam a dramaticidade que envolve a questão da imigração irregular na Europa e, particularmente, na Itália. O tema da acentuação contemporânea dos fluxos de mobilidade humana, impulsionada pela globalização e pelo avanço tecnológico requer reflexão. Nesse cenário, no qual a intensificação dos fluxos migratórios atingiu um ponto no qual a regulamentação jurídica pelos Estados, apresenta sintomas de falência, é preciso pensar, sobretudo, sobre a perspectiva da proteção do imigrante e da garantia de seus direitos.

Com efeito, o que se tem assistido no campo das discussões acerca das migrações internacionais contemporâneas é uma vinculação do assunto ao das soberanias estatais. Nesse rumo, migrar significa transpor essas fronteiras políticas, de modo que, ao fazê-lo, o imigrante se coloca sob a jurisdição do outro Estado que, baseado na sua soberania, define critérios de inclusão e exclusão. Apesar do fortalecimento, na virada do século $\mathrm{XX}$, de vertentes no âmbito do Direito Internacional voltadas à proteção da pessoa que, com base nos Direitos Humanos, buscam fomentar a limitação do poder soberano atribuído aos Estados. A partir da Primeira Guerra Mundial, essa balança começou a pender, mais fortemente, para a soberania nacional, como se tem evidenciado na Europa, onde os países têm regulamentado a movimentação humana, apenas, sob a perspectiva de critérios de admissibilidade e de expulsão que variam, consideravelmente, a depender da conjuntura econômica e política de cada país.

Atualmente, os Estados detêm competência para regulamentar o acesso ao seu território, conforme seus próprios critérios e conveniências, e, assim, recusar a entrada e a permanência de imigrantes, desde que em observância às regras de Direito Internacional. Em outras palavras, ainda que assegurada a soberania aos Estados quando da adoção de normas sobre a admissão e expulsão de estrangeiros em seu território, esse controle 
soberano de suas fronteiras não é absoluto. Com isso, devem os Estados observar suas obrigações jurídicas internacionais, inclusive as que impõem a flexibilização de sua soberania quando o caso exigir amparo ao imigrante.

Essa limitação estatal no estabelecimento das políticas migratórias ganhou destaque, em setembro de 1994, na Conferência Internacional sobre população e desenvolvimento (Conferência de Cairo), quando se preconizou a importância de evitar ações arbitrárias de Estados receptores (políticas racistas e xenofóbicas, ou ainda, de políticas que permitam outras formas de castigo aos imigrantes que excedam a deportação). Por outro lado, no mesmo sentido de documentos anteriores, afirmou-se a necessidade de prevenção de condutas de exploração de imigrantes irregulares.

De modo geral, os instrumentos internacionais seguem disposições bastante próximas que, da mesma forma que visam à proteção dos imigrantes e à aplicação dos Direitos Humanos às demandas vinculadas à mobilidade humana, condenam as condutas de facilitação e promoção da imigração irregular. Inclusive, conforme se destaca na Declaração sobre os Direitos Humanos dos indivíduos que não são nacionais do país em que vivem, aprovada em dezembro de 1985 pela Assembleia Geral da Organização das Nações Unidas, pugna-se que as imigrações irregulares não devam ser regulamentadas, conforme o disposto no artigo $2^{\circ 3}$ do referido documento.

De igual modo, a Convenção Internacional sobre a proteção dos direitos de todos os trabalhadores migran-

3 Artigo 2. 1. Nada na presente Declaração será interpretado de forma a legitimar a entrada e a presença ilegais de um estrangeiro em qualquer Estado, e nenhuma disposição será interpretada de forma a restringir o direito de qualquer Estado a promulgar leis e regulamentos relativos à entrada de estrangeiros e aos termos e condições da sua estadia ou a estabelecer diferenças entre nacionais e estrangeiros. Porém, tais leis e regulamentos não deverão ser incompatíveis com as obrigações jurídicas internacionais do Estado, incluindo as suas obrigações em matéria de direitos humanos (Tradução nossa). Texto original: "Article 2. 1. Nothing in this Declaration shall be interpreted as legitimizing the illegal entry into and presence in a State of any alien, nor shall any provision be interpreted as restricting the right of any State to promulgate laws and regulations concerning the entry of aliens and the terms and conditions of their stay or to establish differences between nationals and aliens. However, such laws and regulations shall not be incompatible with the international legal obligations of that State, including those in the field of human rights." UNITED NATIONS. General Assembly: declaration on the human rights of individuals who are not nationals of the country in which they live. 1985. Disponível em: <http://www.un.org/documents/ga/res/40/a40r144.htm>. Acesso em: 29 nov. 2016. tes e dos membros das suas famílias, adotada em dezembro de 1990 (em vigor apenas desde julho de 2003) não reconhece a regulamentação do imigrante em situação irregular. Por outro lado, ela também promove o "combate" a esse tipo de imigração indesejada pela União Europeia, sem deixar de exigir dos Estados-membros a obrigação de proteger os imigrantes, inclusive os irregulares. Nota-se, com isso, que, apesar desses documentos internacionais insistirem no "combate" à imigração irregular, não é permitido qualquer tratamento desumano ao imigrante nessa condição, bem como qualquer conduta de exploração desses indivíduos em decorrência de atividades criminosas (tráfico de pessoas, escravidão etc.).

Observa-se, assim, na perspectiva internacional, alguns esforços no sentido de proteção ao imigrante sem constituí-lo em sujeito de risco, passível de criminalização. A problemática que orienta o presente artigo, nesse sentido, reside no fato de que, muito embora essas organizações internacionais sejam, atualmente, como os Estados, titulares de personalidade jurídica (e essa condição, em tese, se impor a toda comunidade internacional independentemente da ratificação do tratado constitutivo pelo Estado perante o qual se busca o reconhecimento), o que ocorre na prática é uma personalidade jurídica limitada, que, no campo da imigração, não obstante o fim declarado desses instrumentos, faz com que a proteção dos direitos fundamentais dos imigrantes não seja amplamente aceita pelos Estados. E mais, ao fomentar o controle dos fluxos migratórios e o "combate" à imigração irregular, esses instrumentos internacionais acabam servindo como "meio" (pelos Estados) para a utilização de mecanismos de controle social arbitrários, cujo exemplo maior é a criminalização do imigrante que, no presente estudo, será analisada a partir da realidade italiana.

Como hipótese básica, parte-se da ideia de que, paralelamente ao incremento do discurso da proteção internacional da pessoa a partir de instrumentos multilaterais com base nos Direitos Humanos, o que se verifica, não obstante o fim declarado desses instrumentos — qual seja, a proteção da pessoa, sobretudo do imigrante - é que eles acarretam mecanismos de segregação e criminalização do imigrante ou da imigração, consolidando - particularmente no caso italiano - um modelo de Direito Penal de autor.

Com efeito, os discursos políticos e midiáticos somados às práticas atuais de legislação e policialização 
passam a atuar como uma verdadeira indústria do medo, induzindo a pensar que imigrar é crime. Isso se deve, em grande parte, ao fato de que a imigração é controlada pela polícia e, assim, os imigrantes estão sujeitos a serem presos, ou deportados para seus países de origem, ou confinados em centros de detenção (que são até piores que a prisão). Assim, construídas socialmente de modo negativo, altamente xenofóbico e racista, as respostas institucionais aos processos migratórios não poderiam ser diferentes senão a implementação de medidas que objetivam a criminalização e consequente expulsão dos imigrantes em situação irregular, como se procurará demonstrar ao longo deste artigo.

\section{As Políticas migratóRIas EUROPEIAS E SEUS TRÊS OBJETIVOS}

O tratamento legal da questão da imigração irregular pelos países europeus é analisado por Margarita Martínez Escamilla contra a imigração irregular na União Europeia em três principais objetivos, quais sejam: 1) impedir que os imigrantes saiam de seus países de origem; 2) impedir que os imigrantes que tenham saído de seus países de origem transpassem as fronteiras europeias; 3) forçar os imigrantes que entram no território europeu a deixá-lo.

\subsection{Objetivo 1: impedir que os imigrantes saiam de seus países de origem}

No que se refere ao primeiro objetivo do controle dos fluxos migratórios pela Europa, qual seja, de evitar a saída dos imigrantes de seus países de origem, evidencia-se a tarefa dos países de trânsito e de origem migratório com destino à Europa em conter a imigração, como uma função de guardas das fronteiras. A partir de tal objetivo, observa-se que o controle das fronteiras tem início muito antes do acesso aos países de destino, conforme menciona Ana María López Sala ${ }^{5}$ :

4 MARTÍNEZ ESCAMILLA, Margarita. Inmigración, derechos humanos y política criminal: ¿Hasta donde estamos dispuestos a llegar? Revista para el análisis del Derecho, n. 3, 2009. Disponível em: <http://www.raco.cat/index.php/InDret/article/ viewFile/138050/188695>. Acesso em: 09 jan. 2016.

5 LÓPEZ SALA, Ana María. La ley de la frontera: migraciones internacionales y control de flujos. Revista de Occidente, Madrid, n. 316, p. 102-103, Sep. 2007. en los últimos años ha sido habitual la firma de acuerdos bilaterales y multilaterales de cooperación en el control y la lucha contra la inmigración irregular. Puede afirmarse que hemos asistido a una creciente transnacionalización de esta política y al incremento de su peso en la agenda internacional. Estas iniciativas han tenido un doble alcance, incluyendo tanto acuerdos con otros Estados receptores como con países de trânsito y de origen. La cooperación han sido especialmente intensa en Europa. En contra de la «renacionalización» de las políticas, los acuerdos de Schengen y, posteriormente, de Ámsterdan y Tampere han alentado la colaboración interestatal em materia de justicia, seguridad y fronteras, de lo que da muestra la reciente creación de la Agencia europea de control de las Fronteras Exteriores, Frontex ${ }^{6}$. Estos objetivos se han concretado no sólo em modificaciones normativas, sino en la vigilancia y la financiación conjunta y la colaboración policial.

Os acordos bilaterais firmados pelos Estados-membros com países terceiros possuem papel fundamental na política de controle migratório. Por meio desses acordos de cooperação, os países europeus conseguem impedir a chegada e ter facilitada a expulsão de imigrantes irregulares. Assim, aquele imigrante que consegue transpor fronteira é forçado, por meio de inúmeras medidas, a retornar ao seu país de origem, muitas vezes, inclusive, em condições perigosas e insalubres, como bem refere López Sala?: "la práctica de disuasión más extrema ha sido la interceptación de embarcaciones en aguas internacionales, medidas que han producido un gran rechazo entre las organizaciones civiles y de derecho humanos".

Esses acordos bilaterais têm se transformado em mecanismos de controle para além das próprias fronteiras em que atores não estatais, também, têm se incorporado ao controle das fronteiras, como é o caso das companhias de transporte de passageiros. Segundo López Sala ${ }^{8}$, "las legislaciones de Europa y Norteamérica han tipificado la responsabilidad de la devolución a las compañías aéreas en caso de transportar personas sin la documentación necesaria para entrar en los paí-

6 A Agência Europeia de Gestão da Cooperação Operacional nas Fronteiras Externas dos Estados-Membros da União Europeia (Frontex), é encarregada da cooperação operacional entre os Estados-membros da União Europeia e os países associados de Schengen no controle das fronteiras externas.

7 LÓPEZ SALA, Ana María. La ley de la frontera: migraciones internacionales y control de flujos. Revista de Occidente, Madrid, n. 316, p. 105 , Sep. 2007.

8 LÓPEZ SALA, Ana María. La ley de la frontera: migraciones internacionales y control de flujos. Revista de Occidente, Madrid, n. 316, p. 104 , Sep. 2007. 
ses de destino, transformando de forma indirecta a sus empleados en funcionarios de frontera". A estratégia de limitar o acesso pode ocorrer de diversas formas, inclusive por meio de medidas que dificultem a entrada de solicitantes de asilo, de campanhas informativas com o objetivo de dissuadir a saída dos imigrantes, de políticas de restrições de concessão de vistos, de refúgio e de agrupamento familiar, entre outros.

A impossibilidade de sair de seu país de origem por vias formais pode acarretar consequências terríveis ao indivíduo que tenta transpor fronteiras, como a sua detenção e também o aumento do tráfico de pessoas. Ainda, como se tem registrado nos últimos anos, tal medida de externalização do controle de fronteiras acaba por resultar em milhares de mortes de imigrantes em acidentes marítimos ou terrestres.

O relatório "Viagens Letais", elaborado pela Organização Internacional para as Migrações (OIM), publicado em 14 de junho de 2016, revela que, desde 1996, na tentativa de chegar a um país mais desenvolvido, mais de 60 (sessenta) mil imigrantes morreram ou desapareceram em rotas marítimas e terrestres em todo o mundo. Calcula-se que 5.400 (cinco mil e quatrocentos) imigrantes morreram ou desapareceram em 2015. Até junho de 2016, mais de 3.400 (três mil e quatrocentos) imigrantes perderam a vida em todo mundo e mais de $80 \%$ deles no intento de chegar à Europa pelo mar?

A ineficácia de tal método de controle resta comprovada diante do significativo aumento do número de mortes de pessoas frente a, cada vez maior, dificuldade encontrada ao se tentar sair de seu país de origem, aumentando os riscos assumidos pelos imigrantes, levando, segundo Martínez Escamilla ${ }^{10}$, a "una relación directa entre incremento de las dificultades y número de muertes en el intento".

A União Europeia, por meio desses acordos de readmissão e cooperação, recorre aos Estados que não podem ou que não respeitam os direitos humanos dos

9 INTERNATIONAL ORGANIZATION FOR MIGRATION. Fatal Journeys: Identification and tracing of dead and missing migrants. v. 2, 2016. Disponível em: <https://publications.iom.int/ books/fatal-journeys-volume-2-identification-and-tracing-deadand-missing-migrants $>$. Acesso em: 16 jul. 2016.

10 MARTÍNEZ ESCAMILLA, Margarita. Inmigración, derechos humanos y política criminal: ¿Hasta donde estamos dispuestos a llegar? Revista para el análisis del Derecho, n. 3, 2009. Disponível em: <http://www.raco.cat/index.php/InDret/article/ viewFile/138050/188695>. Acesso em: 09 jan. 2016. refugiados e dos migrantes, para fazer o "trabalho sujo" de interceptação e repatriamento forçado desses sujeitos, em clara violação do Direito Internacional ${ }^{11}$.

Nesse sentido, o Relator Especial da Organização das Nações Unidas (ONU) sobre os Direitos Humanos dos migrantes, François Crépeau, expressou preocupação com os acordos de cooperação bilaterais negociados entre a Itália e seus vizinhos, especialmente a cooperação com a Líbia, devido à falta de padrões mínimos de Direitos Humanos e os inúmeros e frequentes relatos de abusos e violações aos imigrantes. Segundo o Relator, apesar de atualmente suspenso o acordo de 2007 em repercussão ao caso Hirsi Jamaa (caso 1, das considerações iniciais), a cooperação entre os dois Estados foi recentemente reforçada por meio de um processo verbal, preocupando a perpetuação e a possibilidade de novas práticas que violem os Direitos Humanos ${ }^{12}$.

Percebe-se um avanço radical desse processo de externalização das fronteiras, a partir do qual esses acordos de readmissão, que permitem a intercepção de embarcações e consequentes retornos desburocratizados e imediatos de imigrantes que estão na Itália de forma irregular, ocorram sem que haja uma análise prévia da situação de cada indivíduo, evidenciando o total descaso por parte do Estado italiano que se isenta das responsabilidades e parece ignorar as consequências desastrosas de tais ações - muito bem descritas no Caso 1 -, mesmo conhecendo a condenação/reprovação de tais violações pelos instrumentos internacionais.

Por meio dessas políticas, o imigrante fica à mercê do Estado e de suas medidas extraordinárias que não têm o Direito Internacional como fundamento e que visam atender tão somente aos interesses nacionais. Não há nenhuma preocupação com os Direitos Humanos nessas políticas que impedem a chegada, que criminalizam e que expulsam imigrantes irregulares. Essas ações, no entanto, violam princípios e garantias fundamentais humanos e acarretam consequências desastrosas de extremos abusos, violações, discriminações e mortes.

Diante disso, em setembro de 2016, o Parlamento Eu-

11 AMNESTY INTERNATIONAL. Hotspot Italy: how EU's flagship approach leads to violations of refugee and migrant rights. 2016. Disponível em: <https://www.amnesty.org/en/documents/ eur30/5004/2016/en/>. Acesso em: 29 nov. 2016.

12 FRENZEN, Niels. Un special rapporteur on HR of migrants expresses concern over Italy-Libya cooperation on migration. 2012. Migrants at sea. Disponível em: <https://migrantsatsea.org/tag/bilateralimmigration-agreements/>. Acesso em: 24 mar. 2016. 
ropeu e do Conselho adotou ato legislativo, qual seja, o Regulamento 2016/1624, que altera e revoga documentos anteriores no sentido de implementar uma gestão europeia integrada das fronteiras em nível nacional e da União que possua maior eficiência na gestão, vigilância e controle dos fluxos migratórios e das potenciais ameaças nas fronteiras, contribuindo para combater a criminalidade e para garantir um elevado nível de segurança interna na União, reforçando medidas com países terceiros, nomeadamente no âmbito da política comum dos vistos, medidas com países terceiros vizinhos, medidas de controles externos, análises de risco (dados estatísticos) e medidas no âmbito do espaço Schengen e em matéria de regresso.

O respectivo regulamento reconhece e reforça a Agência Europeia de Gestão da Cooperação Operacional nas Fronteiras Externas dos Estados-membros da União Europeia, designada como Frontex, como um dos principais programas na execução da gestão das fronteiras europeias externas. Sua atuação se dá por meio de operações conjuntas e de intervenções rápidas nas fronteiras, bem como da análise de risco, do intercâmbio de informações, das relações com países terceiros e no regresso de retornados, transformando-a em uma agência com responsabilidade partilhada em matéria de gestão das fronteiras externas, alargando, assim, suas atribuições anteriores.

Essas práticas de fomento de identificação e classificação de "perfis de risco", com base em dados estatísticos coletados de forma integrada na União Europeia, bem como a antecipação e a prevenção de supostas ameaças oriundas desses perfis, que criam estereótipos de "inimigos" perigosos e indesejáveis, pautam toda a atuação da Agência Frontex, que define quem são os alvos desse controle, como também quais serão os mecanismos de controle migratório utilizados contra esses sujeitos. Evidencia-se, com isso, uma estrutura de controle para além do "combate" à imigração irregular, que busca, também, a fundamentação da criminalização da imigração e do imigrante. Alimenta-se, assim, a continuidade e reforça-se a lógica do risco atrelada ao imigrante.

\subsection{Objetivo 2: impedir que os imigrantes que tenham saído de seus países de origem transpassem as fronteiras europeias}

O segundo objetivo das políticas migratórias europeias, analisado por Martínez Escamilla ${ }^{13}$, objetiva im-

13 MARTÍNEZ ESCAMILLA, Margarita. Inmigración, dere- permeabilizar as fronteiras de forma a impedir o ingresso dos imigrantes, principalmente daqueles que possam tentar entrar de maneira irregular.

Percebe-se que, atualmente, os controles migratórios de saída em países de origem e trânsito, somados às restrições de entrada na Europa, praticamente impedem, de qualquer maneira, a livre circulação. Por meio dessa política, portanto, a Europa fecha suas fronteiras, selecionando quem entra em seu território.

Nesse contexto, no que tange à seleção dos imigrantes, atenta-se a um outro aspecto na gestão da imigração, qual seja, o desenvolvimento de uma política inspirada fundamentalmente nos interesses econômicos, como bem refere Martínez Escamilla"1: "se admite a quien consideramos que puede ser útil para nuestra economía, una economía que há pasado de prospera a maltrecha". Ou seja, o processo de regulação da imigração na União Europeia ganha uma dimensão laboral de especial relevância, segundo a qual o imigrante se converte em mão de obra barata e flexível, importante para o crescimento econômico.

Esse aspecto do imigrante como força de trabalho informal ganha força quando, na prática, políticas de controle e regulação da imigração irregular passam a ter prioridade em detrimento de políticas de integração e cooperação, resultando em um processo de retirada dos direitos desses sujeitos, como é o caso do processo de despolitização do imigrante, que é fundamental para a sua constituição como um mero instrumento de trabalho que não indica pertencimento, que não indica permanência eterna no país receptor, que caracteriza o imigrante um instrumento de mão de obra que é descartável quando não mais necessário. Nesse rumo, o imigrante, enquanto for útil, é, provisoriamente, aceito. Com isso, quando sua função na sociedade de imigração se esgotar, ele deve retornar ao seu país de origem ${ }^{15}$. Dito de outra forma, como o imigrante deve continuar sendo sempre um imigrante, visto sua natureza total-

chos humanos y política criminal: ¿Hasta donde estamos dispuestos a llegar? Revista para el análisis del Derecho, n. 3, 2009. Disponível em: <http://www.raco.cat/index.php/InDret/article/ viewFile/138050/188695>. Acesso em: 09 jan. 2016.

14 MARTÍNEZ ESCAMILLA, Margarita. Inmigración, derechos humanos y política criminal: ¿Hasta donde estamos dispuestos a llegar? Revista para el análisis del Derecho, n. 3, 2009. Disponível em: <http://www.raco.cat/index.php/InDret/article/ viewFile/138050/188695>. Acesso em: 09 jan. 2016.

15 SAYAD, Abdelmalek. A imigração ou os paradoxos da alteridade. Tradução: Cristina Murachco. São Paulo: EDUSP, 1998. 
mente provisória e utilitária, ele é passível de expulsão a qualquer momento.

Nesse sentido, cientes de que, dificilmente, seriam denunciados, muitos empregadores e empresários inescrupulosos se aproveitam da situação de vulnerabilidade do imigrante, especialmente o imigrante em condição de irregularidade. Este, por viver durante a maior parte do tempo se escondendo, necessita encontrar trabalho, mesmo que em condições nas quais os cidadãos nacionais não aceitariam, como salários extremamente baixos, carga de trabalho bastante superior, enfim, condições que remetem a uma situação de escravidão, e, consequentemente, violam os Direitos Humanos fundamentais desses sujeitos. Além do empregador, outros setores, também, se beneficiam com essas medidas restritivas, como é o caso dos chamados "coiotes", que são aquelas pessoas que auxiliam, mediante pagamento, na travessia de fronteiras pelos imigrantes, seja fornecendo transporte, burlando os controles de fronteiras, entre outros, que acabam aumento seus lucros em razão de políticas mais severas para a entrada de imigrantes.

$\mathrm{Na}$ Itália, a adoção da lei conhecida como Turco-Napolitano, em 1998, prevê a permissão de ingresso e residência de estrangeiros por motivo laboral, concedida pelo prazo que durar o contrato de trabalho e condicionada à estadia no país de acordo com o interesse dos empregadores, de modo que, ao final do contrato, o trabalhador estrangeiro deve retornar ao seu país de origem. Observa-se, com isso, que esses indivíduos são concebidos como força de trabalho e não como indivíduos titulares de direitos humanos, reforçando preconceitos culturais e institucionais, reproduzindo um mecanismo de discriminação e violência ${ }^{16}$. Esse tipo de ação, ainda, em tempos de crises políticas, serve como válvula de escape para atitudes xenófobas e racistas, pois os imigrantes são vistos como competidores ilegítimos, verdadeiros parasitas $^{17}$.

Em resumo, o que se evidencia é um verdadeiro paradoxo entre as políticas adotadas, que, na prática, são de controle e regulação, e a insatisfação generalizada com o aumento dos fluxos migratórios, que crescem conforme

16 GARCIA, Fernanda di Flora. A exceção é a regra: os centros de detenção para imigrantes na Itália. Revista Interdisciplinar da Mobilidade Humana, Brasília, n. 43, p. 235-250, 2014.

17 SPIRE, Alexis. Xenofobia em nome do Estado de bem-estar social. Le Monde Diplomatique Brasil. 2013. Disponível em: <http:// www.diplomatique.org.br/artigo.php?id=1550>. Acesso em: 13 out. 2016. aumentam os controles fronteiriços. Ao mesmo tempo em que a Europa busca impulsionar a economia, ela impede a chegada de imigrantes, ainda que pesquisas indiquem que a imigração pode proporcionar crescimento econômico e contribuir para melhorar as estatísticas de consumo e arrecadação. Apesar de toda influência do cenário econômico e das necessidades do mercado de trabalho, responsáveis pela construção utilitarista do imigrante, percebe-se, sobretudo, uma supremacia da vontade política no que diz respeito à implementação dessas medidas, a qual mantém um discurso securitário que caracteriza os imigrantes como uma ameaça ao Estado e que, ao que parece, por vezes, é sobreposta aos interesses econômicos.

Assim, o que não precisaria ser problemático, conforme aduz Lopes ${ }^{18}$, acaba tomando esse caminho pois, em vez de tomar medidas para ordenar a imigração, "os países potencialmente receptores de mão de obra estão aumentando a altura dos muros de contenção de imigrantes, investindo em policiamento, tecnologia, controle dos mais generalizados e, ainda, pactuando com os países pobres (dos quais pessoas emigram) para que estes países colaborem na repressão da imigração". O mais grave dessa "psicose migratória" é que, as pessoas, ainda que no seu íntimo saibam a verdade, qual seja, de que "boa parte da humanidade está privada dos bens necessários para satisfazer as necessidades básicas de sobrevivência e bem-estar", preferem, "para não ter que atuar para modificar uma realidade de que são beneficiárias", acreditar nessa ideia de "virtual ameaça". E é por isso que, atualmente, já não se trata de apenas defender o mercado de trabalho ou uma certa homogeneidade nacional, mas sim de defender o país de uma nova espécie de ameaça à própria integridade física de seus cidadãos.

A perspectiva de seletividade migratória a partir da qual o imigrante serve como mão de obra para a resolução de problemas pontuais do mercado de trabalho europeu é combinada com a abrangência do ideal securitário em que se busca afastar as ameaças, ou seja, aqueles imigrantes indesejáveis. Com isso, crescem as violações de Direitos Humanos, evidenciadas no aumento dos números de mortes de imigrantes em resultado de violências preconceituosas, também no aumento das

18 LOPES, Cristiane Maria Sbalqueiro. Direito de imigração: o estatuto do estrangeiro em uma perspectiva de direitos humanos. Porto Alegre: Nuria fabris, 2009. p. 49. 
explorações e na degradação dos centros de detenção.

\subsection{Objetivo 3: forçar os imigrantes que entram no território europeu a deixá-lo}

No que tange ao terceiro e último objetivo das políticas de controle de fluxos migratórios definido por Martínez Escamilla ${ }^{19}$, é cada vez mais evidente a criação de mecanismos para fazer com que aquele imigrante que conseguiu transpor a fronteira europeia seja forçado a retornar ao seu país de origem, muitas vezes, inclusive, em condições perigosas e insalubres. Para López Sala ${ }^{20}$,

la práctica de disuasión más extrema ha sido la interceptación de embarcaciones en aguas internacionales, medidas que han producido un gran rechazo entre las organizaciones civiles y de derechos humanos. [...] En el caso europeo la interceptación en alta mar se está convertiendo, paulatinamente, en una prolongación de la vigilancia marítima de la frontera sur y de la ejecución de los acuerdos de devolución.

A partir de tais objetivos, notadamente, a Europa passa a reconhecer a imigração como um problema, atuando na forma de controle e expulsão desses fluxos migratórios, convidando os Estados-membros a conduzir, pela potencial ameaça que representam, a criminalização dos imigrantes indesejados.

Nesse sentido, em maio de 2001, o Conselho da União Europeia adotou um ato legislativo que demonstra o início de uma sequência de documentos que chegaram à utilização de medidas punitivas no tratamento e controle da imigração irregular. A Diretiva 2001/40/ CE buscava legitimidade e maior eficácia de decisões de afastamento de nacionais de países terceiros (imigrantes extracomunitários), bem como o estabelecimento de uma política comum de gestão migratória que conduzisse a um tratamento uniforme nesse sentido de afastamento de extracomunitários.

O objetivo dessa política comum migratória de gerenciamento dos fluxos migratórios era de, por meio de mecanismos de controle atuarial, gerir os riscos decorrentes da associação da imigração irregular com a cri-

19 MARTÍNEZ ESCAMILLA, Margarita. Inmigración, derechos humanos y política criminal: ¿Hasta donde estamos dispuestos a llegar? Revista para el análisis del Derecho, n. 3, 2009. Disponível em: <http://www.raco.cat/index.php/InDret/article/ viewFile/138050/188695>. Acesso em: 09 jan. 2016.

20 LÓPEZ SALA, Ana María. La ley de la frontera: migraciones internacionales y control de flujos. Revista de Occidente, Madrid, n. 316, p. 105 , Sep. 2007. minalidade e demais mal-estares sociais, que, ao final, tornassem eficaz o "combate" à imigração irregular, conforme se observa da análise do artigo $3^{\circ}$ da respectiva diretiva ${ }^{21}$.

Nota-se que, em relação a essa ideal de gestão dos riscos decorrentes dos fluxos migratórios, determinadas condições identificadas como perigosas — imigrantes infratores ou em situação de irregularidade — passaram a fundamentar a necessidade de afastamento desses sujeitos dos demais na comunidade europeia.

Esse movimento de identificação da imigração extracomunitária, essencialmente a irregular, com questões relacionadas à insegurança e à criminalidade a fim de justificar a expulsão desses indivíduos, é evidenciado em documentos como a Diretiva 2002/90/CE, adotada em novembro de 2002, que insiste nessas associações negativas à imigração para reforçar a necessidade de "combate". Além disso, seguindo outros documentos, o respectivo dispositivo determina aos seus Estados-membros a incumbência de criminalizar as condutas de auxílio e facilitação da imigração irregular, conforme o disposto no artigo $1^{\mathrm{o} 22}$.

21 Art. 3. 1. O afastamento referido no artigo 1 abrange os casos seguintes: a) Quando um nacional de um país terceiro for objeto de uma decisão de afastamento baseada em uma ameaça grave e atual para a ordem pública ou para a segurança nacional tomada em caso de: - condenação do nacional do país terceiro pelo Estado-membro autor por uma infração passível de pena de prisão não inferior a um ano; - existência de razões sérias para crer que um nacional de um país terceiro cometeu atos puníveis graves ou de existência de indícios reais de que tenciona cometer atos dessa natureza no território de um Estado-membro. [...] b) Quando o nacional de um país terceiro seja objeto de uma medida de afastamento baseada no descumprimento da regulamentação nacional relativa à entrada ou à permanência de estrangeiros (Tradução nossa). Texto original: "Article 3. 1. The expulsion referred to in Article 1 shall apply to the following cases: (a) a third country national is the subject of an expulsion decision based on a serious and present threat to public order or to national security and safety, taken in the following cases: - conviction of a third country national by the issuing Member State for an offence punishable by a penalty involving deprivation of liberty of at least one year; - the existence of serious grounds for believing that a third country national has committed serious criminal offences or the existence of solid evidence of his intention to commit such offences within the territory of a Member State. [...] (b) a third country national is the subject of an expulsion decision based on failure to comply with national rules on the entry or residence of aliens". EUROPEAN UNION. Council Directive 2001/40/CE. 28 may 2001. Disponível em: <http://eurlex.europa.eu/LexUriServ/ LexUriServ.do?uri=OJ:L:2001:149:0034:0036:PT:PDF>. Acesso em: 29 nov. 2016.

22 Artigo $1^{\circ}$. Infração geral. 1. Os Estados-Membros devem adotar sanções adequadas: a) Contra quem auxilie intencionalmente 
O processo de criminalização da imigração irregular é impulsionado, então, com a adoção da denominada "Diretiva de Regresso" (2008/115/CE), aprovada pelo Parlamento Europeu e o Conselho em dezembro de 2008, propondo, para um maior controle dos fluxos migratórios, normas e procedimentos comuns utilizados para o regresso de imigrantes em situação irregular. O objetivo do referido documento é conceder autonomia procedimental e poder discricionário aos Estados-membros para o regresso, voluntário ou involuntário, de imigrantes irregulares que estejam no território da União Europeia.

O artigo 15 da respectiva Diretiva confere autorização aos Estados-membros para, fundamentado pela lógica do risco, realizar a detenção preventiva dos imigrantes durante o procedimento de expulsão por um período de até 6 (seis) meses, podendo, ainda, tal privação de liberdade ser prolongada pelos Estados-membros por até 12 (doze) meses a mais ${ }^{23}$.

uma pessoa que não seja nacional de um Estado-Membro a entrar ou a transitar através do território de um Estado-Membro, em infração da legislação aplicável nesse Estado em matéria de entrada ou trânsito de estrangeiros; b) Contra quem, com fins lucrativos, auxilie intencionalmente uma pessoa que não seja nacional de um Estado-Membro a permanecer no território de um Estado-Membro, em infração da legislação aplicável nesse Estado em matéria de residência de estrangeiros (Tradução nossa). Texto original: "Article 1. General infringement. 1. Each Member State shall adopt appropriate sanctions on: (a) any person who intentionally assists a person who is not a national of a Member State to enter, or transit across, the territory of a Member State in breach of the laws of the State concerned on the entry or transit of aliens; (b) any person who, for financial gain, intentionally assists a person who is not a national of a Member State to reside within the territory of a Member State in breach of the laws of the State concerned on the residence of aliens." EUROPEAN UNION. Council Directive 2002/90/EC. 28 nov. 2002. Disponível em: <http://eur-lex.europa.eu/LexUriServ/ LexUriServ.do?uri=OJ:L:2002:328:0017:0018:EN:PDF>. Acesso em: 29 nov. 2016.

23 Artigo 15. Detenção 1. A menos que no caso concreto possam ser aplicadas com eficácia outras medidas suficientes, mas menos coercivas, os Estados-membros só podem manter detidos nacionais de países terceiros objeto de procedimento de regresso, a fim de preparar o regresso e/ou efetuar o processo de afastamento, nomeadamente quando: a) Houver risco de fuga; ou b) O nacional de país terceiro em causa evitar ou entravar a preparação do regresso ou o procedimento de afastamento. [...] 5. A detenção mantém-se enquanto se verificarem as condições enunciadas no número $1 \mathrm{e}$ na medida do necessário para garantir a execução da operação de afastamento. Cada Estado-membro fixa um prazo limitado de detenção, que não pode exceder os seis meses. 6. Os Estados-membros não podem prorrogar o prazo a que se refere o número 5 , exceto por um prazo limitado que não exceda os doze meses seguintes, de acordo com a lei nacional, nos casos em que, independentemente de todos os esforços razoáveis que tenham envidado, se preveja que a operação de afastamento dure mais tempo, por força de: a)
Ao autorizar a detenção preventiva do imigrante irregular, o texto do referido documento é um verdadeiro convite ao retrocesso. A severidade da medida administrativa de expulsão resta demonstrada a partir de seus potenciais efeitos negativos, quais sejam, de extremo perigo à integridade física e à vida desses sujeitos expostos a tal ato de deportação que poderá, conforme dispõe o artigo $3^{\circ}$, número 3 , da referida Diretiva, ocorrer ao país de origem, ou a um país de trânsito (ao abrigo de acordos de readmissão comunitários ou bilaterais ou de outras convenções), como também a outro país terceiro, para o qual a pessoa em causa decida regressar, voluntariamente, e no qual seja aceita.

Essas medidas de detenção e expulsão administrativas ainda, de acordo com Brandariz García ${ }^{24}$, se constituem em uma "fraude de etiquetas", ou seja, em razão de seu conteúdo, sentido e notável severidade, essas medidas configuram sanções penais materiais e não administrativas, como são formalmente consideradas. Essa fraude permite que a aplicação, a execução e o controle dessas medidas não estejam "sometidos a las garantías que corresponderían a su gravedad, entre ellas el postulado de proporcionalidad, que debería conducir a una neta distinción de gravedad entre las sanciones aplicables a las infracciones administrativas y las derivadas de la responsabilidad criminal".

Falta de cooperação do nacional de país terceiro em causa; ou b) Atrasos na obtenção da documentação necessária junto de países terceiros (Tradução nossa). Texto original: "Article 15. Detention. 1. Unless other sufficient but less coercive measures can be applied effectively in a specific case, Member States may only keep in detention a third-country national who is the subject of return procedures in order to prepare the return and/or carry out the removal process, in particular when: (a) there is a risk of absconding or (b) the third-country national concerned avoids or hampers the preparation of return or the removal process. [...] 5. Detention shall be maintained for as long a period as the conditions laid down in paragraph 1 are fulfilled and it is necessary to ensure successful removal. Each Member State shall set a limited period of detention, which may not exceed six months. 6. Member States may not extend the period referred to in paragraph 5 except for a limited period not exceeding a further twelve months in accordance with national law in cases where regardless of all their reasonable efforts the removal operation is likely to last longer owing to: (a) a lack of cooperation by the third-country national concerned, or (b) delays in obtaining the necessary documentation from third countries." EUROPEAN PARLIAMENT AND OF THE COUNCIL. Directive 2008/115/ EC. 16 December 2008. Disponível em: <http://eur-lex.europa. eu/LexUriServ/LexUriServ.do?uri=OJ:L:2008:348:0098:0107:en:P DF>. Acesso em: 29 nov. 2016.

24 BRANDARIZ GARCÍA, José Ángel. Sistema penal y control de los migrantes: gramática del migrante como infractor penal. Granada: Comares, 2011. p. 74. 
A detenção administrativa de imigrantes em situação irregular constitui uma privação de liberdade que é materialmente equiparável a uma prisão preventiva, com a particularidade de que possui um prazo máximo de duração estabelecido em lei. Essa afirmação, na ótica de Brandariz García ${ }^{25}$, é comprovada pela frequência com que a medida de detenção tem sido utilizada como função sancionadora, a partir de uma lógica preventiva (geral e especial) que objetiva intimidar o imigrante para que regresse ao seu país de origem ou dissuadir outros migrantes com intento de destino à Europa. Além disso, a aproximação entre o contexto carcerário e os centros de detenção para imigrantes é especialmente evidente em diversos países europeus, nos quais a privação de liberdade dos migrantes irregulares ocorre em celas policiais ou centros penitenciários, com aplicação da legislação carcerária.

\section{Biopolítica e CONTROLE PENAL DE FLUXOS MIGRATÓRIOS NA ITÁLIA: A CONSOLIDAÇÃO DE UM MODELO DE DIREITO PENAL DE AUTOR}

No que tange à política migratória nacional, a Itália é um dos países da União Europeia no qual o processo de controle da imigração irregular se faz de forma mais intensa, muito em razão da sua posição geográfica, que constitui uma extensa fronteira externa que contribui para a entrada irregular de imigrantes. Segundo dados divulgados pela Organização Internacional para as Migrações (OIM), em dezembro de 2016, mais de 352 (trezentos e cinquenta e dois) mil imigrantes e refugiados já haviam ingressado na Europa por via marítima, especialmente pela Itália e Grécia. Em relação a esse total, mais de 176 (cento e setenta e seis) mil chegaram à Itália, e foram registradas 4.244 (quatro mil duzentos e quarenta e quatro) mortes durante a tentativa de travessia pela rota do mar Mediterrâneo central (Itália) ${ }^{26}$.

Até o início dos anos 1980, visando ao fomento do turismo, o governo italiano assumia uma postura ins-

25 BRANDARIZ GARCÍA, José Ángel. Sistema penal y control de los migrantes: gramática del migrante como infractor penal. Granada: Comares, 2011

26 INTERNATIONAL ORGANIZATION FOR MIGRATION. Fatal Journeys: Identification and tracing of dead and missing migrants. v. 2, 2016. Disponível em: <https://publications.iom.int/ books/fatal-journeys-volume-2-identification-and-tracing-deadand-missing-migrants >. Acesso em: 16 jul. 2016. titucional com relação aos estrangeiros de abertura de suas fronteiras, de modo que não existia uma legislação específica de regulamentação da imigração, e o país apenas observava os tratados internacionais dos quais era signatário que visavam à proteção de seus emigrantes. Essa relação de indiferença e sem muitas restrições no que tange ao ingresso e à permanência de imigrantes em seu território começaram a assumir outra conotação após a queda do Muro de Berlim e a desagregação do bloco soviético. A queda do governo comunista da Albânia acarretou um intenso movimento migratório em direção à península itálica, que fora inicialmente apoiado pelas autoridades italianas e pela opinião pública local. Entretanto, com a intensificação desse fluxo e a entrada massiva de albaneses, o discurso político sobre a imigração, de modo geral, mudou de sentido, passando, em um primeiro momento, a identificar os albaneses como responsáveis pelo aumento da criminalidade no país e, posteriormente, ampliando essa concepção a todos os demais estrangeiros. Em um intervalo de tempo de poucos meses, "não se falava mais em refugiados, mas sim em imigrantes 'ilegais' ou 'clandestinos' para definir e caracterizar os indivíduos que entraram recentemente no país, em especial os albaneses, cujas demandas por refúgio e asilo passaram a ser arbitrariamente consideradas ilegítimas" 27 .

Nesse sentido, pode-se afirmar que a Itália, desde a década de 1990, vive mudanças em suas políticas migratórias que transformaram o tratamento e a percepção dos processos migratórios, especialmente no que diz respeito à política de repressão e criminalização dos imigrantes ainda em curso. Desde esse período, conforme menciona Dal Lago ${ }^{28}$, os imigrantes em situação irregular passaram a encontrar no cárcere o destino inevitável de seu percurso migratório, independentemente do fato de haverem cometido crimes ou de sua efetiva periculosidade social.

Desde então, o panorama atual do governo italiano é marcado: a) por medidas excepcionais que se tornam a regra; b) pela constante declaração de estados de emergência; c) pela proliferação de centros de detenção para estrangeiros altamente arbitrários; d) pela criação de leis que determinam uma espécie de direito especial para

27 GARCIA, Fernanda di Flora. A exceção é a regra: os centros de detenção para imigrantes na Itália. Revista Interdisciplinar da Mobilidade Humana, Brasília, n. 43, p. 238, 2014.

28 DAL LAGO, Alessandro. Non-persone: l'esclusione dei migranti in una società global. Milano: Feltrinelli, 2004. p. 32. 
os imigrantes; e) por racismo popular e institucional; f) pela confusão de questões a priori de refúgio e asilo com imigração; e g) pela assustadora violação e consequente derrocada dos Direitos Humanos em relação ao assunto $^{29}$.

Em âmbito legislativo, a adoção da lei conhecida como Turco-Napolitana, em março de 1998, configura a primeira principal alteração na política migratória desse período e que fundamentou as alterações subsequentes, passando a "combater" a imigração irregular através de medidas mais rígidas no controle dos fluxos migratórios. Com base nesta legislação, condutas de facilitação e auxílio à imigração irregular passaram a ser punidas como crime com pena de prisão de até 3 (três) anos e multa.

Além disso, uma das características mais notáveis dessa lei, segundo Garcia ${ }^{30}$, é a adoção da lógica securitária no interior da política migratória. Todas as medidas elencadas na lei "reforçam a visão da migração como gestão dos riscos potenciais, independente da sua natureza objetiva ou da relevância concreta das supostas ameaças". Fortemente baseada pela discriminação, a legislação em tela adota uma severa vigilância e monitoramento com relação aos estrangeiros ao transformar em regra geral a detenção forçada para fins de expulsão. Assim, não sendo possível o imediato processo de expulsão, deve o imigrante ser detido em um dos centros de detenção temporária até que os procedimentos para a expulsão sejam definidos. Nesse rumo, atenta-se para o fato de esses centros de detenção administrativa para imigrantes não funcionarem como espaços de acolhimento temporário, mas sim como verdadeiras prisões, nas quais os imigrantes são mantidos em confinamento até que seja realizada a sua expulsão ou deportação.

Durante anos esses centros de detenção, hoje denominados, sem nenhum eufemismo, de "Centros de Identificação e Expulsão (CIEs)" — alteração que aproximou os termos daquilo que de fato tais espaços são —, vêm sendo denunciados por organização internacionais e nacionais, por inúmeras violações aos Direitos Humanos, pelo aumento do uso da detenção arbitrária de imigrantes e, ainda, por ataques violentos de mora-

29 GARCIA, Fernanda di Flora. A exceção é a regra: os centros de detenção para imigrantes na Itália. Revista Interdisciplinar da Mobilidade Humana, Brasília, n. 43, p. 235-250, 2014.

30 GARCIA, Fernanda di Flora. A exceção é a regra: os centros de detenção para imigrantes na Itália. Revista Interdisciplinar da Mobilidade Humana, Brasília, n. 43, p. 240, 2014. dores e militantes da extrema direita que são resistentes aos processos migratórios, como vem ocorrendo dos centros de detenção na Itália ${ }^{31}$.

Segundo o relatório anual do Human Rights Watch $^{32}$, a Itália, no ano de 2015, esperava criar seis locais conhecidos como hotspots, que são espécies de centros de recepção e processamento de pedidos de asilo, que trabalham sob coordenação da Frontex e do Gabinete Europeu de Apoio ao Asilo, selecionando e registrando quem são as pessoas que pretendem pedir proteção internacional e quem são os imigrantes irregulares sujeitos à expulsão, sendo estes entregues às autoridades nacionais para o devido repatriamento, de modo a dar um melhor andamento na gestão dos fluxos migratórios. No entanto, no ano de 2016, a própria Human Rights Watch ${ }^{33}$, entre outras organizações, como a Amnesty Internationa $\beta^{34} \mathrm{e}$ European Council for Refugees and Exiles ${ }^{35}$, criticaram as condições e tratamentos dispensados aos migrantes nos centros de processamento italianos, que estão cada vez mais, na tentativa de deslocamento forçado, cometendo abusos aos Direitos Humanos dos imigrantes, que incluem o uso excessivo da força pela polícia, a detenção arbitrária, expulsões coletivas, tortura, maus-tratos, etc.

É justamente nesses espaços de confinamento ilegais (centros de detenção) que são aplicados procedimentos específicos, como uma espécie de "direito especial", de maneira que delitos da mesma espécie possuem penas distintas de acordo com "quem" os comete. Nesses locais os imigrantes são excluídos da cidadania, não possuem garantias jurídicas por meio das quais possam recorrer da decisão que estabelece sua detenção ou para

31 AMNESTY INTERNATIONAL. Hotspot Italy: how EU's flagship approach leads to violations of refugee and migrant rights. 2016. Disponível em: < https://www.amnesty.org/en/documents/ eur30/5004/2016/en/>. Acesso em: 29 nov. 2016.

32 HUMAN RIGHTS WATCH. Europe's Refugee Crisis: report November 16, 2015. An Agenda for Action. Disponível em: < https:// www.hrw.org/report/2015/11/16/europes-refugee-crisis/agendaaction>. Acesso em: 29 nov. 2016.

33 HUMAN RIGHTS WATCH. Restore Rights Values to Migration Policy. 2016. Disponível em: <https://www.hrw.org/ news/2016/12/13/eu-restore-rights-values-migration-policy $>$. Acesso em 29 nov. 2016.

34 AMNESTY INTERNATIONAL. Hotspot Italy: how EU's flagship approach leads to violations of refugee and migrant rights. 2016. Disponível em: < https://www.amnesty.org/en/documents/ eur30/5004/2016/en/>. Acesso em: 29 nov. 2016.

35 EUROPEAN COUNCIL FOR REFUGEES AND EXILES. The implementation of the hotspots in Italy and Greece. Report 2016. Disponível em: <http://www.ecre.org/wp-content/uploads/2016/12/ HOTSPOTS-Report-12.2016..pdf>. Acesso em: 29 nov. 2016. 
questionar o tratamento degradante ao qual são submetidos, não se configuram mais como sujeitos de direitos humanos, afirmando uma mudança da lei que deixa de ser igualitária e universal ao caracterizar um direito especial, exclusivo para determinadas categorias da população. Nesses espaços os indivíduos são mantidos em termos puramente vitais, de mera manutenção da sua existência, sem qualquer possibilidade de manifestar sua subjetividade ou sua identidade ${ }^{36}$. Essa condição de pura vida nua, ou seja, de vida cuja (in)existência é, absolutamente, irrelevante para o sistema, segundo Gar$\mathrm{cia}^{37}$, corresponde a duas estratégias diversas de desumanização: a "primeira é aquela ordinária, normal, legal, do controle social nas instituições totais. A segunda é aquela extrema e destrutiva da guerra total, dos campos de concentração, da tortura em larga escala e do extermínio organizado".

Com efeito, os refugiados, segundo Agamben ${ }^{38}$, cujo número nunca parou de crescer ao longo do século XX, representam, no ordenamento do Estado-nação moderno, um elemento inquietante, uma vez que, "rompendo a continuidade entre homem e cidadão, entre nascimento e nacionalidade, eles põem em crise a ficção originária da soberania moderna. Exibindo à luz o resíduo entre nascimento e nação, o refugiado faz surgir por um átimo na cena política aquela vida nua que constitui seu secreto pressuposto".

Do mesmo modo, a população migrante, transformada em mera vida nua (homo sacer), evidencia, claramente, o caráter biopolítico ${ }^{39}$ das medidas punitivas contemporâneas voltadas a esses sujeitos, que são capazes de exercer um controle dos fluxos migratórios a tal ponto que anulam esses indivíduos como cidadãos de direitos, transformando-os em súditos à mercê dos desígnios do poder soberano. Objetos de pura dominação, excluídos da lei e do controle do judiciário, portanto.

Nesse panorama, no qual o Estado detém poder de intervenção cada vez mais amplo, o racismo no in-

36 GARCIA, Fernanda di Flora. A exceção é a regra: os centros de detenção para imigrantes na Itália. Revista Interdisciplinar da Mobilidade Humana, Brasília, n. 43, p. 235-250, 2014.

37 GARCIA, Fernanda di Flora. A exceção é a regra: os centros de detenção para imigrantes na Itália. Revista Interdisciplinar da Mobilidade Humana, Brasília, n. 43, p. 244, 2014.

38 AGAMBEN, Giorgio. Homo sacer: o poder soberano e a vida nua I. Tradução: Henrique Burigo. Belo Horizonte: UFMG, 2010.

39 FOUCAULT, Michel. Em defesa da sociedade: curso no Collège de France (1975-1976). Tradução: Maria Ermantina Galvão. 2. ed. São Paulo: WMF M. Fontes, 2010. terior das relações sociais e na esfera institucional e a existência desses espaços de detenção preventivos que privam os imigrantes do estatuto jurídico de cidadão, que aniquilam, que destroem, punindo-os coletivamente, reduzindo-os a pura vida nua, acabam se tornando espaços de exceção nos quais qualquer ato de violência não é considerado um crime ou delito passível de condenação.

Essas medidas excepcionais de internação, confinamento e execução, passam a ser vistas como constitutivas do ordenamento jurídico-político: são confundidas com a própria normalidade, implicando a normalização da exceção e da desumanização, pela via da produção de campos (instituições totais), constituindo uma linguagem contemporânea dos efeitos do capitalismo tardio, "que gera o risco, a insegurança, o medo, a incerteza, a debilidade, a crise do Welfare State, que efetua o controle difuso, a vigilância constante, entre outros"40.

Com efeito, apesar de o ordenamento jurídico italiano regulamentar o estado de exceção apenas em casos de guerra, segundo Garcia ${ }^{41}$, a política italiana, a partir da Lei no 225 de 1992, pode delegar poderes emergenciais a órgãos especiais com o objetivo de superar determinadas situações de crise. Com base nesse dispositivo, a prática da legislação governamental por meio de decretos-lei transformou-se em regra na Itália, tornando rotineiro o uso de medidas excepcionais, a tal ponto que, ao constituírem a forma normal de legislação, acabam culminando alterações jurídicas, políticas e sociais.

Nesse sentido, ainda que não tenha havido de fato a suspensão do ordenamento jurídico, o Estado italiano, assim como outras democracias modernas, estabelece poderes extraordinários por meio de leis ordinárias, mesmo sem o recurso formal da declaração do estado de exceção. Com isso, o regime da emergência, por meio do qual os processos migratórios são compreendidos por meio da ótica securitária, passa a impor alterações permanentes na estrutura jurídica.

Nesse rumo, a partir do ano de 2002, com o advento da Lei 189, conhecida como "Lei Bossi-Fini", o governo italiano passou a potencializar o "combate" à

40 GARCIA, Fernanda di Flora. A exceção é a regra: os centros de detenção para imigrantes na Itália. Revista Interdisciplinar da Mobilidade Humana, Brasília, n. 43, p. 248, 2014.

41 GARCIA, Fernanda di Flora. A exceção é a regra: os centros de detenção para imigrantes na Itália. Revista Interdisciplinar da Mobilidade Humana, Brasília, n. 43, p. 246, 2014. 
imigração irregular, por meio do endurecimento da lei migratória, dificultando a entrada e reduzindo os direitos dos imigrantes ${ }^{42}$.

No ano de 2008, o governo de Silvio Berlusconi, então primeiro-ministro da Itália, propôs o chamado Pacchetto sicurezza, que promoveu novas políticas migratórias relacionadas às políticas de segurança pública, dispondo de um conjunto de medidas voltadas ao controle dos fluxos migratórios, de criminalização e repressão do imigrante que se encontrasse no país em situação irregular, decretando pena de multa, privação de liberdade e consequente expulsão desses sujeitos ${ }^{43}$.

A partir de então, a Itália criminaliza, com pena de multa ou de prisão em certas condições de gravidade, o ato de atravessar, irregularmente, suas fronteiras, conforme prevê a Lei 125, promulgada em julho de 2008, que introduziu um novo parágrafo (11-bis) no artigo 61 do Código Penal, estabelecendo uma circunstância de agravamento de pena para o delito praticado por um imigrante em situação irregular ${ }^{44}$.

No ano de 2009, destaca-se a promulgação da Lei 94, relativa à entrada e permanência irregular de estrangeiro no território italiano, que alterou o Decreto Legislativo 286, de 25 de julho de 1998 (Testo unico delle disposizioni concernenti la disciplina dell'immigrazione e norme sulla condizione dello straniero) e que está diretamente ligada à questão da segurança nacional. A referida lei inseriu o artigo 10-bis, que institui crime punível com pena de multa que pode ser transformada em prisão e consequente expulsão do país, ao prever:

\section{Art. 10-bis. (Ingresso e soggiorno illegale nel territorio dello Stato).}

1. Salvo che il fatto costituisca più grave reato, lo straniero che fa ingresso ovvero si trattiene nel territorio dello Stato, in violazione delle disposizioni del presente testo unico nonché di quelle di cui all'articolo 1 della legge 28 maggio 2007, n. 68, è

42 DI MARTINO, Alberto et al. The criminalization of irregular immigration: law and practice in Italy, 2013. Disponível em: <http:// www.wiss-lab.dirpolis.sssup.it/ files/2013/05/Libro-dirpolis-1. pdf $>$. Acesso em: 12 jan. 2016.

43 DI MARTINO, Alberto et al. The criminalization of irregular immigration: law and practice in Italy, 2013. Disponível em: <http:// www.wiss-lab.dirpolis.sssup.it/ files/2013/05/Libro-dirpolis-1. pdf $>$. Acesso em: 12 jan. 2016.

44 Art. 1. Modifiche al codice penale. 1. Al codice penal sono apportate le seguenti modificazioni: [...] f) all'articolo 61, primo comma, dopo il numero 11 e' aggiunto il seguinte: 11-bis. I'avere il colpevolfe commesso il fato mentre si trova ilegalmente sul território nazionale. PARALAMENTO ITALIANO, Legge n. 125, 2008. punito con l'ammenda da 5.000 a 10.000 euro. $\mathrm{Al}$ reato di cui al presente comma non si applica l'articolo 162 del codice penale ${ }^{45}$.

Para Cecilia Valbonesi ${ }^{46}$, a pena de multa prevista no artigo 10-bis constitui uma punição mais simbólica do que dissuasiva, uma vez que é direcionada a uma população, em sua maior parte, insolvente, o que resultaria na ineficácia da medida. Por essa razão, o dispositivo legal, que busca "parecer" não tão severo, uma vez que a pena se daria em caráter pecuniário e não privativo de liberdade, sugere a única intenção do legislador, qual seja, de expulsar o imigrante do território italiano.

Expulsar e neutralizar os estrangeiros são, claramente, os objetivos buscados pelo legislador. Nesse sentido, a Lei 94/2009, também, modificou o parágrafo 5-ter do artigo 14 do Texto Único sobre a Imigração, para criminalizar a violação de uma ordem de expulsão, permanecendo, ilegalmente, o estrangeiro em território italiano:

Art. 14.

$[\cdots]$

m) all'articolo 14, i commi 5-bis, 5-ter, 5-quater e 5-quinquies sono sostituiti dai seguenti:

5-bis. Quando non sia stato possibile trattenere lo straniero presso un centro di identificazione ed espulsione, ovvero la permanenza in tale struttura non abbia consentito l'esecuzione con l'accompagnamento alla frontiera dell'espulsione o del respingimento, il questore ordina allo straniero di lasciare il territorio dello Stato entro il termine di cinque giorni. L'ordine è dato con provvedimento scritto, recante l'indicazione delle conseguenze sanzionatorie della permanenza illegale, anche reiterata, nel territorio dello Stato. L'ordine del questore può essere accompagnato dalla consegna all'interessato della documentazione necessaria per raggiungere gli uffici della rappresentanza diplomatica del suo Paese in Italia, anche se onoraria,

45 Art. 10-bis. (Entrada e permanência ilegal no Estado). 1. Salvo se o fato constituir infração penal mais grave, o estrangeiro que ingressa ou permanece no território do Estado, em violação das disposições do presente texto único, além das previstas no art. $1^{\circ}$ da Lei $\mathrm{n}^{\circ} 68$ de 28 de maio de 2007, é punido com multa de 5.000 a 10.000 euros. Ao presente parágrafo não se aplica o art. 162 do Código Penal (tradução nossa). PARLAMENTO ITALIANO. PARLAMENTO ITALIANO. Decreto Legislativo 25 luglio 1998, n. 286. Testo unico delle disposizioni concernenti la disciplina dell'immigrazione e norme sulla condizione dello straniero. Disponível em: <http:// www.camera.it/parlam/leggi/deleghe/98286dl.htm>. Acesso em: 09 jan. 2016.

46 VALBONESI, Cecilia. Il reato di immigrazione clandestina nell'ordinamento italiano fra "diritto penale del nemico" e "multiculturalismo". Revista de Estudios Jurídicos, n. 12, 2012. Disponível em: <http://revistaselectronicas.ujaen.es/index.php/rej/article/ view/831>. Acesso em: 28 jan. 2017. 
nonchè per rientrare nello Stato di appartenenza ovvero, qndo ciò non sia possibile, nello Stato di provenienza.

5-ter. Lo straniero che senza giustificato motivo permane illegalmente nel territorio dello Stato, in violazione dell'ordine impartito dal questore ai sensi del comma 5- bis, è punito con la reclusione da uno a quattro anni se l'espulsione o il respingimento sono stati disposti per ingresso illegale nel territorio nazionale ai sensi dell'articolo 13 , comma 2, lettere a) e c), ovvero per non aver richiesto il permesso di soggiorno o non aver dichiarato la propria presenza nel territorio dello Stato nel termine prescritto in assenza di cause di forza maggiore, ovvero per essere stato il permesso revocato o annullato. Si applica la pena della reclusione da sei mesi ad un anno se l'espulsione è stata disposta perchè il permesso di soggiorno è scaduto da più di sessanta giorni e non ne è stato richiesto il rinnovo, ovvero se la richiesta del titolo di soggiorno è stata rifiutata, ovvero se lo straniero si è trattenuto nel territorio dello Stato in violazione dell'articolo 1 , comma 3 , della legge 28 maggio 2007, n. 68. In ogni caso, salvo che lo straniero si trovi in stato di detenzione in carcere, si procede all'adozione di un nuovo provvedimento di espulsione con accompagnamento alla frontiera a mezzo della forza pubblica per violazione all'ordine di allontanamento adottato dal questore ai sensi del comma 5-bis. Qualora non sia possibile procedere all'accompagnamento alla frontiera, si applicano le disposizioni di cui ai commi 1 e 5-bis del presente articolo nonchè, ricorrendone i presupposti, quelle di cui all'articolo 13, comma 3.

5-quater. Lo straniero destinatario del provvedimento di espulsione di cui al comma 5-ter e di un nuovo ordine di allontanamento di cui al comma 5-bis, che continua a permanere illegalmente nel territorio dello Stato, è punito con la reclusione da uno a cinque anni. Si applicano, in ogni caso, le disposizioni di cui al comma 5-ter, terzo e ultimo periodo.

5-quinquies. Per i reati previsti ai commi 5-ter, primo periodo, e 5-quater si procede con rito direttissimo ed è obbligatorio l'arresto dell'autore del fato ${ }^{47}$.

47 Art. 14. [... m) no artigo 14, os parágrafos 5-bis, 5-ter, 5-quater e 5-quinquies são substituídos pelo seguinte: 5-bis. Se não for possível a detenção do estrangeiro em um centro de identificação e expulsão, ou se ainda não houver condições deste ser escoltado até a fronteira para fins de expulsão ou repulsão, o Comissário notificará o estrangeiro a deixar o território do Estado no prazo de cinco dias. A ordem é dada por escrito, mencionando expressamente as consequências sancionatórias de sua permanência ilegal, inclusive a sua reincidência, no território do Estado. A notificação do Comissário pode ser acompanhada da entrega da documentação necessária para envio à sede da missão diplomática de seu país na Itália, além dos honorários devidos, bem como para se obter os seus dados de qualificação, quando isto não for possível a partir do seu Estado de origem. 5-ter. O estrangeiro que sem justificação permanecer ilegalmente no território italiano, em descumprimento à ordem dada pelo Comissário, nos termos do parágrafo 5-bis, será punido com pena de prisão
Além da desproporcionalidade na punição ao estrangeiro em razão da mera incapacidade de cumprir a ordem de expulsão, o artigo 14 demonstra a instrumentalização do Direito Penal para a gestão dos fluxos migratórios. Como refere Valbonesi ${ }^{48}$, o legislador, no seu intento de criminalizar a condição pessoal do autor, ou seja, daquele que, no momento da infração, está presente no território italiano em situação de irregularidade, pune um "modo de ser" que não é sintomático de uma efetiva periculosidade social.

Em 2010, a Corte Constitucional italiana, por meio do acórdão no 249, declarou inconstitucional a circunstância agravante da presença irregular do imigrante introduzida pelo pacote de segurança, em 2008, e mantida nas alterações legislativas de 2009, pelo governo italiano. $\mathrm{Na}$ ocasião, a medida foi compreendida, sobretudo, como responsável pelo abarrotamento do judiciário e ineficaz no controle e gestão dos fluxos migratórios irregulares.

Apesar de ser alvo de inúmeras críticas e de ser bastante rejeitada pelos partidos mais conservadores e

de um a quatro anos, se a expulsão ou repulsão tiver sido efetivada após a entrada ilegal no país, com fundamento no art. 13 , parágrafo $2^{\circ}$, alineas "a" e "c", ou por não ter solicitado autorização de permanência ou não ter declarado a sua presença no Estado, no prazo fixado, não havendo motivo de força maior, ou se a permissão foi revogada ou cancelada. Aplica-se a pena de prisão de seis meses a um ano se a expulsão foi ordenada porque a autorização de residência expirou há mais de sessenta dias e não houve solicitação de sua renovação, ou se o pedido de autorização de residência foi negado, ou se o estrangeiro está detido no Estado em violação ao art. $1^{\circ}$, parágrafo $3^{\circ}$, da Lei no 68 de 28 de maio de 2007. Em qualquer caso, a não ser que o estrangeiro esteja detido na prisão, haverá uma nova ordem de expulsão, com acompanhamento policial até a fronteira, em razão de violação à ordem de expulsão emitida pelo Comissário referida no parágrafo 5-bis. Se não for possível o acompanhamento policial até a fronteira, aplicar-se-á o disposto nos parágrafos 1 e 5-bis do presente artigo, bem como, caso as condições sejam satisfeitas, aplicar-se-á o disposto no art. 13 , parágrafo $3^{\circ}$. 5-quater. $\mathrm{O}$ estrangeiro destinatário da ordem de expulsão prevista no parágrafo 5-ter e de uma nova ordem de remoção estatuída conforme o parágrafo 5-bis, que continue a permanecer ilegalmente no Estado, será punido com pena de prisão de um a cinco anos. Aplica-se, em qualquer caso, o disposto no parágrafo 5-ter, terceiro e último período. 5-quinquies. Para os delitos previstos nos parágrafos 5-ter, primeiro período, e 5-quater, serão processados e julgados em rito de urgência, sendo obrigatória a detenção do autor do fato (grifo e tradução nossa). PARLAMENTO ITALIANO. Legge 15 luglio 2009, n. 94. Disposizioni in materia di sicurezza pubblica. Disponível em: <http://www.parlamento.it/parlam/leggi/09094l.htm>. Acesso em: 09 jan. 2016.

48 VALBONESI, Cecilia. Il reato di immigrazione clandestina nell'ordinamento italiano fra "diritto penale del nemico" e "multiculturalismo". Revista de Estudios Jurídicos, n. 12, 2012. Disponível em: <http://revistaselectronicas.ujaen.es/index.php/rej/article/ view/831>. Acesso em: 28 jan. 2017. 
xenofóbicos, em abril de 2014, o Parlamento Italiano aprovou a Lei 67, delegando ao Poder Executivo a emanação de um Decreto, em um período de até dezoito meses a partir de maio de 2014 (data de entrada em vigor da lei), para a descriminalização e revogação de uma série de infrações penais, entre elas a de imigração irregular, que é transformada em infração administrativa conforme dispõe o artigo $2^{\circ}$, número 3 , alínea b:

\section{Art. 2.}

Delega al Governo per la reforma dela disciplina sanzionatoria.

\section{$[\cdots]$}

b) abrogare, trasformandolo in illecito amministrativo, il reato previsto dall'articolo 10bis del testo unico delle disposizioni concernenti la disciplina dell'immigrazione e norme sulla condizione dello straniero, di cui al decreto legislativo 25 luglio 1998, n. 286, conservando rilievo penale alle condotte di violazione dei provvedimenti amministrativi adottati in materia ${ }^{49}$.

Em novembro de 2015, o governo italiano aprovou o projeto de execução do Decreto Legislativo que revoga o uso indiscriminado do Direito Penal no controle dos fluxos migratórios, conforme dispõe o referido relatório:

\begin{abstract}
Il provvedimento, in sintesi, mira a depenalizzare, ossia a trasformare taluni reatiinillecitiamministrativi rispondendo ad una scelta di politica criminale, da tempo sollecitata, anche in relazione alle sottese esigenze economiche e sociali, di deflazionare il sistema penale, sostanziale e processuale, in ossequio ai principi di frammentarietà, offensività e sussidiarietà della sanzione penale.
\end{abstract}

Ocorre que, até o momento, apesar da promulgação pelo governo italiano dos correspondentes Decretos Legislativos (n. 7 e n. 8) em janeiro de 2016, que descriminalizam o ingresso e a permanência irregular no território italiano, e já decorrido o prazo para a entrada em

49 Art. 2. Delega ao Governo a reforma das regras relativas às sanções: [...] b) Revogar, convertendo em infração administrativa, o delito previsto no artigo 10-bis do Texto único das disposições que regulamentam a imigração e as normas sobre a condição do estrangeiro, nos termos do Decreto Legislativo de 25 de julho de 1998 , n. 286, mantendo como crime a conduta de violação das medidas administrativas adotadas nesta matéria (tradução nossa). PARLAMENTO ITALIANO. Legge 28 aprile 2014, n. 67. Deleghe al Governo in materia di pene detentive non carcerarie e di reforma del sistema sanzionatorio. Disposizioni in materia di sospensione del procedimento con messa ala prova e nei confronti degli irreperibili. Disponível em: <http://www.avvocatomassimoscrascia. it/wordpress/wp-content/uploads/2014/06/LEGGE-67-2014. htm>. Acesso em: 29 nov. 2016. vigor da lei, qual seja, em fevereiro de 2016, a descriminalização ainda não é aplicada. Isso decorre do fato de que o tema da descriminalização da imigração irregular configura matéria sensível para os interesses envolvidos, os quais parecem entender que o processo criminal é indispensável para uma melhor regulação dos processos migratórios, para que os cidadãos não pensem que se está descuidando da segurança ${ }^{50}$.

O fato é que o imigrante irregular, por natureza excluído em razão da sua condição, também se vê encurralado pelo Direito Penal que, de acordo com Martínez Escamilla $a^{51}$, é chamado para a proteção da população europeia em "defesa" dos imigrantes irregulares e não na defesa dos direitos humanos, revelando, com isso, uma nova razão do tipo penal, qual seja, de "combate" à imigração irregular. Definitivamente, o Direito Penal se converte em um instrumento de política migratória.

Com isso, o imigrante irregular, subalterno e vulnerável, é selecionado. negativamente, em todos os planos da vida social, inclusive por meio da atuação do sistema punitivo $^{52}$, que age buscando reprimi-lo, impedi-lo e exclui-lo. Nesse contexto, o imigrante irregular acaba por ser inserido — pelos fatores já expostos acima na categoria de indivíduos perigosos, de inimigos, e que por serem assim "identificados", não precisam praticar nenhum ato perigoso para estabelecer a "verdade" sobre a sua condição de população perigosa. Logo, o Estado priva-lhes, unilateralmente, da proteção legal que corresponde a qualquer pessoa sujeita às leis nacionais $\mathrm{e}$ internacionais, pois se tratam de não cidadãos, ou seja, "de personas no consideradas como sujetos, de seres humanos no conceptualizados dentro del marco de una cultura política en la que la vida humana goza de derechos legales y está asegurada por leyes — seres humanos que por lo tanto no son humanos" $" 53$.

Nota-se que, nesse estado de coisas, o Direito Penal

50 FRIGENI, Luisa. La depenalizzazione si arresta di fronte al reato di immigrazione clandestina. Federalismi.it. Rivista di diritto pubblico italiano, comparato, europeo, n. 15, 2016.

51 MARTÍNEZ ESCAMILLA, Margarita. Inmigración, derechos humanos y política criminal: ¿Hasta donde estamos dispuestos a llegar? Revista para el análisis del Derecho, n. 3, 2009. Disponível em: <http://www.raco.cat/index.php/InDret/article/ viewFile/138050/188695>. Acesso em: 09 jan. 2016.

52 BRANDARIZ GARCÍA, José Ángel. Sistema penal y control de los migrantes: gramática del migrante como infractor penal. Granada: Comares, 2011.

53 BUTLER, Judith. Vida pracaria: el poder del duelo y la violência. Buenos Aires: Paidós, 2006. p. 108. 
é utilizado como instrumento de massa de manobra, que há muito perdeu sua legitimidade e compatibilidade com o próprio Estado de Direito. É nesse sentido que ocorre a expansão do Direito Punitivo em relação à imigração irregular. No intento de dar respostas eficientistas aos medos e inseguranças da população, e com o objetivo de evitar que os riscos se convertam em situações concretas de perigo, o Direito Penal passa a ser utilizado como instrumento preventivo, levando ao reconhecimento, segundo Massimo Donini ${ }^{54}$, da "transición de un Estado de derecho a un Estado de prevención”, ou seja, "un Estado que por raziones de seguridad pide a los ciudadanos la renuncia a los derechos que tienen frente al Estado mismo, anticipando la intervención invasiva de los poderes públicos a todo nivel, y no sólo en vista de particulares, circunscritas emergencias".

Desse modo, o tratamento penal direcionado à imigração irregular, segundo Doninii ${ }^{55}$, apresenta uma política de exclusão penalmente armada, na qual se evidencia a adoção de um modelo de Direito Penal voltado para a exclusão dos imigrantes. Trata-se de um modelo de Direito Penal autoritário, orientado pela lógica do "inimigo" e, portanto, incompatível com o Estado de Direito. Isso porque esse modelo propõe um estado policialesco, com a retirada de garantias e direitos que, além de não resolver os problemas relacionados à criminalidade, objetiva tão somente a exclusão do sujeito não desejado. Em suma, trata-se de um modelo que "convierte a los adversarios en "no personas" destinadas a ser neutralizadas o excluidas sin culpabilidad, o en todo caso sin una 'culpa' correspondiente a la sanción que es aplicada, transformando la respuesta penal en la más típica de un derecho penal de autor" ${ }^{\prime 26}$.

Esse modelo de Direito Penal, voltado ao inimigo, conforme menciona Ferrajoli ${ }^{57}$, inverte a lógica segundo a qual o Direito Penal pune determinados "tipos de

54 DONINI, Massimo. El ciudadano extracomunitario: de "objeto material" a "tipo de autor" en el control penal de la inmigración. Revista Nuevo Foro Penal, v. 5, n. 72, p. 205-206, 2009.

55 DONINI, Massimo. El ciudadano extracomunitario: de "objeto material" a "tipo de autor" en el control penal de la inmigración. Revista Nuevo Foro Penal, v. 5, n. 72, p. 170-210, 2009.

56 DONINI, Massimo. El ciudadano extracomunitario: de "objeto material" a "tipo de autor" en el control penal de la inmigración. Revista Nuevo Foro Penal, v. 5, n. 72, p. 170-210, 2009.

57 FERRAJOLI, Luigi. El derecho penal del enemigo y la disolución del derecho penal. Revista del Instituto de Ciencias Jurídicas de Puebla A. C., n. 19, p. 5-22, 2007. Disponível em: <http://www. icipuebla.com/revista/IUS19/IUS\%2019IND.pdf>. Acesso em: 12 jan. 2016. ação" e não determinados "tipos de pessoas", ou seja, segundo a qual os indivíduos são punidos pelo que "fazem ou deixam de fazer" e não por aquilo que "são". Nesse modelo, a predeterminação legal e a averiguação judicial do fato punível cedem posto à identificação do inimigo, que, inevitavelmente, ao não estar mediada pela prova de atos específicos de inimizade, se resolve na identificação, na captura e na condenação dos suspeitos. Com efeito, "el enemigo debe ser castigado por lo que es y no por lo que hace". Logo, "el presupuesto de la pena no es la realización de un delito, sino una cualidad personal determinada en cada ocasión con criterios puramente potestativos como los de 'sospechoso' o 'peligroso'. Ni sirven pruebas sino diagnosis y prognosis políticas".

De acordo com Donini ${ }^{58}$, o Direito Penal do autor consiste em um Direito Penal em que "la razón de ser de la punición (o de una respuesta sancionatoria agravada) no consiste en el hecho cometido, sino en el tipo de autor", ou porque, "falta el hecho que es sustituido por un sujeto 'antijurídico', o porque el 'hecho' existe pero es sintoma de un juicio sobre el autor: es verdad que no se quiere la comisión del 'hecho', pero porque en realidad es su autor quien resulta indeseable".

Essa identificação de determinados grupos de pessoas como inimigos e/ou fontes de perigo, que criminaliza determinada forma de "ser" do autor (no caso em comento a condição de ser imigrante irregular) e não um fato delituoso cometido, configura um modelo de Direito Penal de autor mascarado dentro dos regulamentos do Direito Penal do fato. Isso representa um retrocesso inadmissível, uma vez que tal modelo de Direito Penal não respeita a dignidade da pessoa humana, bem como não reconhece direitos humanos fundamentais.

O ressurgimento desse modelo de Direito Penal, de controle preventivo e excludente, é nitidamente evidenciado na perspectiva contemporânea de controle dos fluxos migratórios, que consiste na securitização da imigração, ou seja, na tentativa de gestão dos riscos mediante a regulação, a seleção, a manipulação e a eliminação da população migratória, o que denota a institucionalização do controle biopolítico ${ }^{59}$ sobre o imigrante,

58 DONINI, Massimo. El ciudadano extracomunitario: de "objeto material" a "tipo de autor" en el control penal de la inmigración. Revista Nuevo Foro Penal, v. 5, n. 72, p. 192, 2009.

59 FOUCAULT, Michel. Em defesa da sociedade: curso no Collège de France (1975-1976). Tradução: Maria Ermantina Galvão. 2. ed. São Paulo: WMF M. Fontes, 2010. 
que o torna passível dessas políticas antes mesmo de cometer qualquer crime.

As medidas de detenção administrativa, criminalização e expulsão de imigrantes irregulares caracterizam o objetivo de normalização desse conjunto de sujeitos, que, ao final, viabilizam um controle absoluto dos corpos, um controle biopolítico "donde el poder soberano disciplina el estatus de quien no tiene derechos de ciudadanía y se manifiesta al Estado por ser simplemente un «cuerpo», con su identidad física, sexual, étnica, geográfica, etc., sobre el cual el poder dicta las leyes, comenzando así a asignar o negar derechos en razón de las «corpóreas» o, en el tipo penal, de proveniencia geográfica" ${ }^{30}$.

Os imigrantes irregulares sujeitos a esse controle biopolítico restam, extremamente, vulnerabilizados, privados de todos os direitos relacionados à existência humana, sem qualquer proteção ou garantia jurídico-política, passíveis de toda e qualquer forma de violência. São "vidas nuas", ou seja, não cidadãos (inimigos) que devem ser excluídos. São, nessa lógica, objetos de pura dominação.

\section{Considerações Finais}

O medo e a insegurança, transformados na base da agenda política internacional contemporânea, tem permitido a consolidação de políticas marcadas pela violência. Estas políticas - bastante evidentes no que se refere ao campo do controle de fluxos migratórios pelos países centrais europeus - afrontam, diretamente, os direitos e garantias fundamentais de determinados grupos de pessoas, e são contrárias, inclusive, aos valores sobre os quais as democracias europeias encontram-se assentados. Nesse cenário de paranoia securitária, as políticas de controle, pautadas pela lógica da guerra, evidenciam a produção de "inimigos" que são necessários para a legitimação da violência dispensada pelos Estados.

Em um contexto tal, os imigrantes, especialmente os irregulares, são percebidos como fontes inesgotáveis de riscos, transformando-se, com isso, em objetos de políticas nebulosas de marginalização e repressão, como é o

60 DONINI, Massimo. El ciudadano extracomunitario: de "objeto material" a "tipo de autor" en el control penal de la inmigración. Revista Nuevo Foro Penal, v. 5, n. 72, p. 170-210, 2009. caso da política de criminalização da imigração irregular adotada pela legislação italiana, analisada ao longo do texto. Como se procurou demonstrar — confirmando-se a hipótese inicial esboçada nas considerações introdutórias - a instalação frequente do estado de exceção nos Estados Democráticos de Direito torna-se a principal responsável por esse nexo entre sistemas incompatíveis entre si, como são as democracias parlamentares e os regimes totalitários, o que permite que a exceção atue como o dispositivo por meio do qual o soberano poderá capturar a vida através de uma exclusão inclusiva a partir da qual o imigrante irregular se converte em mera "vida nua", exposto a toda forma de violência. Revela-se, nesse contexto, além do abandono da vida humana pelo direito, a existência de uma vontade soberana com capacidade de suspensão da ordem democrática e do direito.

O controle e a vigilância, que produzem binarismos como imigrante/nacional, ganham proporções desastrosas em consequência das novas formas de racismo, o que os leva a atuar incansavelmente na tentativa de eliminar as alteridades consideradas ameaçadoras e rebeldes, as quais, na sua tentativa de fuga, ativam seu potencial subversivo, tornando-se, reflexamente, objetos perigosos aos dispositivos de controle e vigilância.

Do exposto, é possível afirmar que as políticas migratórias europeias contemporâneas, principalmente as políticas migratórias italianas, exercem um papel que produz efeitos claramente negativos, como a ausência da inclusão desses grupos de indivíduos, a promoção indireta de agressões xenofóbicas e racistas, e perigos para os fundamentos jurídicos e institucionais da própria sociedade. Os riscos resultantes desse processo, portanto, acabam se tornando maiores do que a ameaça atribuída aos imigrantes.

Em definitivo, alguns Estados-membros da União Europeia - particularmente a Itália, analisada na presente pesquisa -, têm edificado, a partir da cultura do medo que altera a realidade e a percepção social sobre a insegurança, novas estratégias voltadas à segurança nacional que avançam sobre liberdades individuais, bem como a adoção de uma nova política criminal no tratamento à imigração irregular de ampliação da intervenção penal, consolidando um modelo de direito penal de autor. 


\section{REFERÊNCIAS}

AGAMBEN, Giorgio. Homo sacer: o poder soberano e a vida nua I. Tradução: Henrique Burigo. Belo Horizonte: UFMG, 2010.

AMNESTY INTERNATIONAL. Hotspot Italy: how EU's flagship approach leads to violations of refugee and migrant rights. 2016. Disponível em: <https:// www.amnesty.org/en/documents/eur30/5004/2016/ en/>. Acesso em: 29 nov. 2016.

BRANDARIZ GARCÍA, José Ángel. Sistema penal y control de los migrantes: gramática del migrante como infractor penal. Granada: Comares, 2011.

BUTLER, Judith. Vida pracaria: el poder del duelo y la violência. Buenos Aires: Paidós, 2006.

DAL LAGO, Alessandro. Non-persone: l'esclusione dei migranti in una società global. Milano: Feltrinelli, 2004.

DI MARTINO, Alberto et al. The criminalization of irregular immigration: law and practice in Italy. 2013. Disponível em: <http://www.wiss-lab.dirpolis.sssup.it/ files/2013/05/Libro-dirpolis-1.pdf $>$. Acesso em: 12 jan. 2016.

DONINI, Massimo. El ciudadano extracomunitario: de "objeto material" a "tipo de autor" en el control penal de la inmigración. Revista Nuevo Foro Penal, v. 5, n. 72, p. 170-210, 2009.

EUROPEAN COUNCIL FOR REFUGEES AND EXILES. The implementation of the hotspots in Italy and Greece. Report 2016. Disponível em: <http://www.ecre. org/wp-content/uploads/2016/12/HOTSPOTS-Report-12.2016..pdf>. Acesso em: 29 nov. 2016.

EUROPEAN COURT OF HUMAN RIGHT. Case of Hirsi Jamaa and others v. Italy. 2012. Disponível em: <http://hudoc.echr.coe.int/>. Acesso em: 23 jan. 2016.

EUROPEAN PARLIAMENT AND OF THE COUNCIL. Directive 2008/115/EC. 16 December 2008. Disponível em: <http://eur-lex.europa.eu/ LexUriServ/LexUriServ.do?uri=OJ:L:2008:348:0098:0 107:en:PDF>. Acesso em: 29 nov. 2016.

EUROPEAN UNION. Council Directive 2001/40/CE. 28 may 2001. Disponível em: <http://eurlex.europa. eu/LexUriServ/LexUriServ.do?uri=OJ:L:2001:149:003 4:0036:PT:PDF>. Acesso em: 29 nov. 2016.

EUROPEAN UNION. Council Directive 2002/90/EC.
28 nov. 2002. Disponível em: <http://eur-lex.europa. eu/LexUriServ/LexUriServ.do?uri=OJ:L:2002:328:001 7:0018:EN:PDF>. Acesso em: 29 nov. 2016.

FERRAJOLI, Luigi. El derecho penal del enemigo y la disolución del derecho penal. Revista del Instituto de Ciencias Jurídicas de Puebla A. C., n. 19, p. 5-22, 2007. Disponível em: <http://www.icipuebla.com/revista/ IUS19/IUS\%2019IND.pdf>. Acesso em: 12 jan. 2016.

FOUCAULT, Michel. Em defesa da sociedade: curso no Collège de France (1975-1976). Tradução: Maria Ermantina Galvão. 2. ed. São Paulo: WMF M. Fontes, 2010.

FRENZEN, Niels. Un special rapporteur on HR of migrants expresses concern over Italy-Libya cooperation on migration. 2012. Migrants at sea. Disponível em: <https:// migrantsatsea.org/tag/bilateral-immigration-agreements/>. Acesso em: 24 mar. 2016.

FRIGENI, Luisa. La depenalizzazione si arresta di fronte al reato di immigrazione clandestina. Federalismi. it. Rivista di diritto pubblico italiano, comparato, europeo, n. 15, 2016.

GARCIA, Fernanda di Flora. A exceção é a regra: os centros de detenção para imigrantes na Itália. Revista Interdisciplinar da Mobilidade Humana, Brasília, n. 43, p. 235 250, 2014.

HELLER, Charles; PEZZANI, Lorenzo. Situ Studio: report on the "Left-To-Die Boat". 2012. Disponível em: <https://www.fidh.org/IMG/pdf/fo-report.pdf>. Acesso em: 28 jan. 2017.

HUMAN RIGHTS WATCH. Europe's Refugee Crisis: report November 16, 2015. An Agenda for Action. Disponível em: <https://www.hrw.org/ report/2015/11/16/europes-refugee-crisis/agendaaction>. Acesso em: 29 nov. 2016.

HUMAN RIGHTS WATCH. Everyday intolerance: Racist and xenophobic violence in Italy. 2011. Disponível em: < https://www.hrw.org/report/2011/03/21/ everyday-intolerance/racist-and-xenophobic-violenceitaly>. Acesso em: 29 nov. 2016.

HUMAN RIGHTS WATCH. Restore Rights Values to Migration Policy. 2016. Disponível em: <https://www. hrw.org/news/2016/12/13/eu-restore-rights-valuesmigration-policy>. Acesso em 29 nov. 2016.

INTERNATIONAL ORGANIZATION FOR MIGRATION. Fatal Journeys: Identification and tracing of 
dead and missing migrants. v. 2, 2016. Disponível em: $<$ https://publications.iom.int/books/fatal-journeysvolume-2-identification-and-tracing-dead-and-missingmigrants>. Acesso em: 16 jul. 2016.

LOPES, Cristiane Maria Sbalqueiro. Direito de imigração: o estatuto do estrangeiro em uma perspectiva de direitos humanos. Porto Alegre: Nuria fabris, 2009.

LÓPEZ SALA, Ana María. La ley de la frontera: migraciones internacionales y control de flujos. Revista de Occidente, Madrid, n. 316, Sep. 2007.

MARTÍNEZ ESCAMILLA, Margarita. Inmigración, derechos humanos y política criminal: ¿Hasta donde estamos dispuestos a llegar? Revista para el análisis del Derecho, n. 3, 2009. Disponível em: <http://www.raco.cat/ index.php/InDret/article/viewFile/138050/188695>. Acesso em: 09 jan. 2016.

PARLAMENTO ITALIANO. Decreto Legislativo 25 luglio 1998, n. 286. Testo unico delle disposizioni concernenti la disciplina dellimmigrazione e norme sulla condizione dello straniero. Disponível em: <http:// www.camera.it/parlam/leggi/deleghe/98286dl.htm>. Acesso em: 09 jan. 2016.

PARLAMENTO ITALIANO. Legge 15 luglio 2009, n. 94. Disposizioni in materia di sicurezza pubblica. Disponível em: <http://www.parlamento.it/parlam/ leggi/09094l.htm>. Acesso em: 09 jan. 2016.

PARLAMENTO ITALIANO. Legge 24 luglio 2008, $n$. 125. Conversione in legge, con modificazioni, del decreto-legge 23 maggio 2008, n. 92, recante misure urgenti in materia di sicurezza pubblica. Disponível em: <http://www.camera.it/parlam/leggi/08125l.htm>. Acesso em: 09 jan. 2016.

PARLAMENTO ITALIANO. Legge 28 aprile 2014, n. 67. Deleghe al Governo in materia di pene detentive non carcerarie e di reforma del sistema sanzionatorio. Disposizioni in materia di sospensione del procedimen- to con messa ala prova e nei confronti degli irreperibili. Disponível em: <http://www.avvocatomassimoscrascia.it/wordpress/wp-content/uploads/2014/06/ LEGGE-67-2014.htm>. Acesso em: 29 nov. 2016.

PARLAMENTO ITALIANO. Legge 30 luglio 2002, n. 189. Modifica alla normativa in materia di immigrazione e di asilo. Disponível em: <http://www.camera.it/ parlam/leggi/021891.htm>. Acesso em: 29 nov. 2016.

PARLAMENTO ITALIANO. Legge 6 marzo 1998, $n$. 40. Disciplina dell'immigrazione e norme sulla condizione dello straniero. Disponível em: <http://www.camera.it/parlam/leggi/980401.htm>. Acesso em: 29 nov. 2016.

SAYAD, Abdelmalek. A imigração ou os paradoxos da alteridade. Tradução: Cristina Murachco. São Paulo: EDUSP, 1998.

SPIRE, Alexis. Xenofobia em nome do Estado de bem-estar social. Le Monde Diplomatique Brasil, 2013. Disponível em: < http://www.diplomatique.org.br/artigo. php?id=1550>. Acesso em: 13 out. 2016

UNITED NATIONS. General Assembly: declaration on the human rights of individuals who are not nationals of the country in which they live. 1985. Disponível em: <http://www.un.org/documents/ga/res/40/a40r144. htm>. Acesso em: 29 nov. 2016.

VALBONESI, Cecilia. Il reato di immigrazione clandestina nell'ordinamento italiano fra "diritto penale del nemico" e "multiculturalismo". Revista de Estudios Jurídicos, n. 12, 2012. Disponível em: <http:// revistaselectronicas.ujaen.es/index.php/rej/article/view/831>. Acesso em: 28 jan. 2017.

ZAFFARONI, Eugenio Raúl. Em busca das penas perdidas. A perda da legitimidade do sistema penal. Tradução: Vânia Romano Pedrosa e Amir Lopes da Conceição. Rio de Janeiro: Revan, 2001. 
Para publicar na Revista de Direito Internacional, acesse o endereço eletrônico www.rdi.uniceub.br ou www.brazilianjournal.org.

Observe as normas de publicação, para facilitar e agilizar o trabalho de edição. 